\title{
I. Die Anfänge des Nationalsozialistischen Kraftfahrkorps und der Motor-SA 1931-1933
}

„Im Zeitalter der Maschine kann eine Volksbewegung nicht darauf verzichten, sich selbst eine Organisation zu schaffen, die alle Kraftfahrer mit ihren Fahrzeugen umfaßt. " ${ }^{1}$ Dieses Postulat setzte die NSDAP mit der Aufstellung eines eigenen Automobilkorps und spezieller SA-Motorstürme Anfang der dreißiger Jahre um. Im ersten Teil dieses Kapitels werden die organisatorische Entwicklung und die Aufgaben der motorisierten Formationen von den Anfängen bis zur NSMachtübernahme 1933 beschrieben.

Ausgehend vom Selbstverständnis der Motor-SA und des NSKK als „Propagandawerkzeuge" steht im zweiten Teil die Werbewirksamkeit der Einsätze im Wahljahr 1932 im Blickpunkt. Als Rahmen dient dabei nicht nur der politische und gesellschaftliche Kontext, sondern auch die technische Entwicklung der damaligen Zeit. Was bedeuteten Politik und Propaganda unter den Bedingungen der fortschreitenden Technisierung der Gesellschaft, zu der die Motorisierung zu zählen war?

Um die Besonderheiten des NSKK und der Motor-SA im Umgang mit der Propaganda einschätzen zu können, wird danach der Frage nachzugehen sein, ob die SA bevorzugt motorisierte Formationen einsetzte, oder ob andere Wehrverbände die sich bietenden Möglichkeiten des Transports und der Mobilitätssteigerung in ähnlicher Weise nutzten. ${ }^{2}$

\section{Die organisatorische Entwicklung}

\section{Der Vorläufer: Das Nationalsozialistische Automobilkorps (NSAK) 1930-1931}

Der Beginn des organisierten Kraftfahrwesens der NSDAP reicht bis zu den Anfängen der nationalsozialistischen Bewegung zurück. Im Jahre 1922 gründete Christian Weber, Mitglied der Parteileitung der NSDAP, eine Transportabteilung für Aufgaben der Obersten SA-Führung (OSAF). Die Mittel zur Beschaffung der ersten Lastwagen stellte der frühe Förderer der Bewegung, Dietrich Eckart, zur

1 NSAK-Kreisstaffelführer Alfred Hoffmann im Völkischen Beobachter vom 17. 2. 1931: „N.S.A.K“.

2 Ein Problem meiner, sowie der meisten historischen Analysen im Bereich nationalsozialistischer Propaganda besteht darin, dass der Blick auf den Absender der Propaganda konzentriert ist und die konkrete Wirkung und Aufnahme beim Rezipienten schwer messbar ist. Zudem findet kein durchgängiger Vergleich der Propagandamethoden der linken Gruppierungen mit denen der Nationalsozialisten statt. Die in diesem Kapitel angestellten Vergleiche sind daher nur ein erster Überblick. Zu Forschungslücken im Bereich nationalsozialistischer Propaganda vgl. Hennig: Anmerkungen zur Propaganda der NSDAP gegenüber SPD und KPD. 
Verfügung. Er war es auch, der die Erlaubnis zur Benutzung von Fahrzeugen bei befreundeten Firmeninhabern einholte. Damit war der Einsatz größerer SA-Abteilungen bei Werbeversammlungen möglich. ${ }^{3}$ Theodor Oppermann betont in seinem Buch zur Geschichte des Nationalsozialistischen Kraftfahrkorps von 1936 die wichtige Rolle des Transportwesens bei politischen Aktionen in der Frühzeit der Bewegung:

„Besonders am 9. November 1923 erwies sich der motorisierte Einsatz als geradezu mitentscheidend. Mit 15 Zügen wurden die SA-Staffeln in Bataillonsstärke zum Bürgerbräukeller befördert, und zwar so überraschend, dass der Führer dort ungehindert handeln konnte. "4

Nach dem Parteitag 1929, auf dem der Ausbau der OSAF beschlossen worden war, erhielt der Verwalter der Hilfskasse und Organisator des Transportwesens Martin Bormann den Auftrag, Satzungen für ein zu gründendes Automobilkorps auszuarbeiten. ${ }^{5} \mathrm{Um}$ nicht auf das wankende Wohlwollen der Automobilbesitzer in Fragen der Bereitstellung von Kraftfahrzeugen für die Zwecke der NSDAP und der SA angewiesen zu sein, verfügte Adolf Hitler im Frühjahr 1930 die Aufstellung einer vollmotorisierten Einheit mit dem Namen: „Nationalsozialistisches Automobil-Korps“ (NSAK). Die Bezeichnung erinnert an das ehemalige „Kaiserlich freiwillige Automobilkorps" aus dem Ersten Weltkrieg. Dabei handelte es sich um einen Zusammenschluss von über 400 Automobilisten, die dem preußischen Kriegsministerium während des Krieges einen mobilen Beförderungs- und Meldedienst zur Verfügung stellten. ${ }^{6}$ Es ist wahrscheinlich, dass eine "gedankliche Brücke“ $z$ wischen den Organisationen in der Namensgebung bestanden hat. ${ }^{7} \mathrm{Zu}$ -

3 Vgl. Mitteilungsblatt Kreis München der NSDAP vom 14. 1. 1937: „Voraus den Kameraden...“, StA München, NSDAP 1321.

4 Oppermann: Unter den Sturmstandern, S. 13. Beim Hitler-Putsch 1923 wurden parteieigene Kraftfahrzeuge aus dem Bestand der Transportabteilung, Mietfahrzeuge und auch beschlagnahmte Kraftwagen verwendet; vgl. Gordon: Hitlerputsch 1923. Machtkampf in Bayern 1923-1924, S. 65, 237 f.; Auflösung der NSDAP 1923 (undatiertes Dokument), StA München, Pol. Dir. München 6722; Verzeichnis der Staatsanwaltschaft über die beim Putsch verwendeten Kraftfahrzeuge vom 5. 1. 1924, StA München, Pol. Dir. München 6713.

5 Vgl. Oppermann: Unter den Sturmstandern, S. 13.

6 Im Jahre 1905 wurde nach Verhandlungen des Deutschen Automobilclubs mit dem Prinzen Heinrich von Preußen und dem preußischen Kriegsministerium das „Deutsche freiwillige Automobilkorps“ gegründet. Die Mitglieder stellten ihre Kraftwagen für militärische Übungen wie das Kaisermanöver zur Verfügung. Zu Beginn des Ersten Weltkrieges wurde das Korps in „Kaiserlich freiwilliges Automobilkorps“ umbenannt. Die Mitglieder, darunter Fritz und Wilhelm Opel, Graf Arco und E. Büssing, wurden in den Offiziersrang erhoben. Von 1916 an erhielt das Korps den Charakter einer rein militärischen Formation und nannte sich jetzt „Kaiserliches Kraftfahrkorps“. Das Korps wurde den Kraftfahrtruppen als Ersatzorganisation angegliedert und 1918 aufgelöst; vgl. Isbert: 30 Jahre Auto, S. 140-155 und Pawelitzki: Das Kaiserliche Freiwillige Automobil-Corps und das Kaiserliche Kraftfahrer Korps.

7 Vgl. Otto Wagener: Hitler aus nächster Nähe, S. 64. Otto Wagener, Stabschef der SA 1929-1930, Leiter der wirtschaftspolitischen Abteilung der Reichsleitung der NSDAP 1931-1933, gibt in seinen Erinnerungen ein Gespräch mit Franz Pfeffer von Salomon wieder, das er 1929 über die Motorisierung der SA geführt hat. Darin erwähnte Wagener als Vorbild für das NSAK das vor dem Ersten Weltkrieg aufgestellte Automobilkorps. 
dem verbreitete die Bezeichnung „Korps“, in Anlehnung an die Reichswehr, eine militärische Aura, die von der OSAF bewusst angestrebt worden war.

\section{Der Aufbau des NSAK: Erste Satzungen und Richtlinien}

Die Satzungen des Nationalsozialistischen Automobilkorps erschienen am 1. April 1930. ${ }^{8}$ Der erste Korpsführer des NSAK war in Personalunion der Chef des Stabes der SA, Franz Pfeffer von Salomon. ${ }^{9}$ In den Statuten wurde das Korps als Vereinigung von „Mitgliedern und Freunden der nationalsozialistischen Freiheitsbewegung" definiert, die sich verpflichten, ihre Kraftwagen für Aufgaben der Partei zur Verfügung zu stellen. Dazu zählten die Beförderung einzelner Führer der Partei und ganzer SA-Abteilungen sowie die Nachrichtenübermittlung. Außerdem verpflichteten sich die Beitrittswilligen, wenn möglich, nur die Tankstellen und Reparaturwerkstätten von Korpsmitgliedern aufzusuchen. Sie erhielten dort einen Rabatt von $10 \% .{ }^{10}$ Die Mitgliedschaft stand jedem "nationalgesinnten Deutschen " offen, der im Besitz eines Pkw, eines Motorrads, eines Lkw oder einer Kraftzugmaschine war.

Das NSAK wurde mit der Gründung im April 1930 geographisch in sieben Bereiche gegliedert: NSAK-Bereich Ost (Berlin-Charlottenburg), NSAK-Bereich Nord (Hannover), NSAK-Bereich Mitte (Dresden), NSAK-Bereich West (Kassel), NSAK-Bereich Ruhr (Elberfeld), NSAK-Bereich Süd (München), NSAKBereich Österreich (Wien). ${ }^{11}$ Diese Aufteilung zeigt das frühe Bemühen der OSAF nach festen Organisationsstrukturen ihrer Unterabteilungen.

Adolf Hitler ernannte den ehemaligen Reichswehrmajor und Teilnehmer am Hitlerputsch 1923, Adolf Hühnlein, Mitte Dezember 1930 zum Chef des Kraftfahrwesens der SA und stellvertretenden Korpsführer des NSAK. Als erfahrener ehemaliger Frontoffizier konnte sich Hühnlein als Mann der Praxis gegenüber Martin Bormann, dem Bürokraten, durchsetzen. ${ }^{12}$ Nach den Worten Bormanns befand sich das NS-Automobilkorps noch in den „Kinderschuhen“, als er es dem Parteigenossen Hühnlein übergab. ${ }^{13}$ Es zählte schätzungsweise 300 Mitglieder. Die absolute Zahl der für die Partei zur Verfügung stehenden Kraftfahrer lag zu dieser Zeit um vieles höher, denn jeder SA-Sturm hatte Kraftfahrer in seinen Rei-

8 Vgl. Oppermann: Unter den Sturmstandern, S. $8 \mathrm{ff}$.

9 Krenzlin: Das NSKK, S. 9.

10 Vgl. ebenda, S. 11.

11 Die Bereiche waren nach Größe und Mitgliederbestand weiter unterteilt. Die Unterführer wurden durch die OSAF-Stellvertreter ernannt; vgl. Oppermann: Unter den Sturmstandern, S. 10. Das NSAK war wie auch später das NSKK bis 1933 in Wien als Verein eingetragen. Vereinszweck war die Zusammenfassung aller „vaterländisch gesinnten“ deutschösterreichischen Staatsbürger, die ein Kfz besaßen. Den Vorsitz hatte Kurt von Barisani, der spätere Führer der Motorgruppe Ostmark; ÖStA Wien, BKA, Generaldirektion für die öffentliche Sicherheit, Verein, 139492-31, Kt. 2473.

12 Vgl. Krenzlin: Das NSKK, S. 10. Bormann als Initiator des NSAK erhielt gleich nach Hitler die Mitgliedsnummer 2; vgl. Lang: Der Sekretär, S. 57, 254. Zur Biografie von Adolf Hühnlein vgl. S. 122-131 dieser Arbeit.

13 Vgl. Oppermann: Unter den Sturmstandern, S. 13. 
hen und konnte auf Sympathisanten mit Fahrzeugen zurückgreifen. ${ }^{14}$ Kostenlose Leihwagen wurden der NSDAP aus den Reihen der Spediteure, Bauunternehmer, Brauereibesitzer, Großhändler, Forstwirte und anderer Berufsgruppen, die Geschäftswagen unterhielten, zur Verfügung gestellt. ${ }^{15}$

Da die Entwicklung des Automobilkorps nur stockend in Gang kam, erließ die SA im März 1931 Richtlinien für den weiteren Ausbau des Korps, die den Aufbau und den Zweck der Organisation genauer bestimmten. ${ }^{16}$ Darin wird die Bedeutung motorisierter Aufzüge für die politische Propaganda deutlich hervorgehoben:

„Die Motorisierung der Bewegung macht uns unabhängig von anderen Verkehrsmitteln, die versagen könnten. Sie erhöht den Aktionsradius der politischen Propaganda und ist für Gauund Parteitage unentbehrlich. Eine in mustergültiger Ordnung fahrende Kraftwagenkolonne mit fliegenden Sturmfahnen und Wimpeln ist von stärkster propagandistischer Wirkung."

Um die Mobilität der Bewegung zu steigern und ihre Propagandawirkung zu verstärken, war das NS-Automobilkorps beauftragt, alle NS-Kraftfahrer und Freunde der Bewegung in seinen Reihen zusammenzuführen. Aus diesem Sammelbecken, so die Zielvorgabe, könnten dann die SA und die SS die nötigen Kraftfahrer und Fahrzeuge zur Bildung von Motorstürmen und -staffeln entnehmen. Das NSAK sollte sein Augenmerk auf die Werbung von nationalsozialistischen Kraftfahrern richten und die Aufstellung der Motorstürme der SA und SS durch Weitergabe der Mitgliederlisten unterstützen. ${ }^{18}$ In den Richtlinien wurde erstmals die Absicht bekundet, die wirtschaftliche Organisation so auszubauen, dass für die Mitglieder des NSAK nicht mehr die Notwendigkeit bestehe, Mitglied anderer Automobilverbände zu sein. Durch die Aufnahme wirtschaftlicher Interessen in den Aufgabenkatalog wollte die Korpsführung die Attraktivität des Korps steigern und trat damit in Konkurrenz zu den bestehenden Automobilclubs. Für die juristische Beratung wurde die Sachkenntnis des Nationalsozialistischen Juristenbundes in Anspruch genommen. Zum Aufbau einer technischen Beratung griff das Korps auf NSDAP-nahe Sachverständige zurück. Die Leitung einer technischen Beratungsstelle des Korps lag in den Händen des Diplomingenieurs Erwin Kraus ${ }^{19}$.

Unterhalb der Korpsführung wurden „Bereichführer“ eingesetzt, die künftig den Gruppenführern der SA in Motorisierungsfragen und in der Aufstellung von Motorstürmen Hilfestellung geben sollten. Der Bereichführer der Gruppe seinerseits wurde durch Bereichführer der Untergruppen, der Gaue oder durch Bezirksführer der Ortsgruppen unterstützt. Besondere Sorgfalt kam der Auswahl des Be-

14 Vgl. Mitteilungsblatt Kreis München der NSDAP vom 14. 1. 1937: „Voraus den Kameraden...“, StA München, NSDAP 1321.

15 Vgl. Blackbourn: „Die meisten von ihnen hatten Räder“, S. $149 \mathrm{f}$.

16 Am 14.3. 1931 erschienen die Richtlinien für den weiteren Ausbau des NSAK; vgl. Oppermann: Unter den Sturmstandern, S. 24; Mitteilungsblatt Kreis München der NSDAP vom 14. 1. 1937: „Voraus den Kameraden...“, StA München, NSDAP 1321.

17 Zit nach: Oppermann: Unter den Sturmstandern, S. 24.

18 Es dürfe aber nicht sein, dass Organe des NSAK in die Motorstürme "hineinbefehlen“, ebenda, S. 25.

19 Zur Biografie von Erwin Kraus vgl. S. $131 \mathrm{f}$. 
reichführers zu. Es sollte sich um eine Persönlichkeit handeln, die in Kraftfahrerkreisen einen Namen hatte, die rhetorisches Talent besaß und einen „repräsentativen Wagen" fuhr. ${ }^{20}$ Die Kriterien, denen die Bereichführer, später die Landesführer des NSKK, entsprechen sollten, lassen Rückschlüsse auf die Zielgruppe der Mitglieder zu. Kraftfahrzeugbesitzer, die einer bessergestellten Schicht angehörten, wollte man nicht durch rohes SA-Gebaren abschrecken, sondern unter „ihresgleichen" belassen. Eine Persönlichkeit mit gesellschaftlichem Renommee konnte die angestrebte Verbindung von politischen Zielen mit gesellschaftlichen und sportlichen Interessen am glaubwürdigsten verkörpern. Zu den Personen, die das Kraftfahrkorps 1931 nach außen vertraten, zählten beispielsweise der in Bayern bekannte Sportflieger Eberhard von Conta als Landesführer im Gau Hochland, der Hannoveraner Verleger Theodor Oppermann als Landesführer im Gau Nordsee, der Ingenieur beim Dampfkessel-Überwachungsverein Heller als Bereichfüher in Braunschweig und der Automobilhändler Georg von Walthausen ${ }^{21}$ im Bereich Düsseldorf. ${ }^{22}$

Auf die Zielgruppe abgestimmt, wurde in den Richtlinien vorgegeben, „möglichst viele fördernde und leistungsfähige Mitglieder" für das Korps zu gewinnen und dabei in Kauf zu nehmen, dass nicht alle Mitglieder des Korps sich auch dem Motorsturm anschließen werden. ${ }^{23}$ Die Zahl der leistungsstarken Beitragszahler erhielt Priorität vor einer aktiven Dienstleistung für die Bewegung. Dies entsprach nicht dem Ethos des politischen Kämpfers, doch stellten Fahrzeuge und ihre Besitzer ein wichtiges Potenzial dar, das, aus Sicht der Parteistrategen, zumindest in finanzieller Hinsicht und als Kraftfahrzeugreserve genutzt werden musste.

\section{Das Nationalsozialistische Kraftfabrkorps (NSKK) 1931-1933}

Kaum waren die Richtlinien zum Aufbau des NSAK in Kraft, erschien am 20. April 1931 eine Verordnung zur Umbenennung des "Nationalsozialistischen Automobil-Korps" in "Nationalsozialistisches Kraftfahr-Korps" (NSKK). Als Hühnlein seinem technischen Berater Kraus die Neuerung schriftlich mitteilte, schrieb er „Herr Hitler wünscht weiterhin“ 24 , was darauf hindeutet, dass die Umbenennung direkt auf Hitler zurückgeht. Bis zu diesem Zeitpunkt dominierten die Autofahrer das Bild des Automobilkorps. Die neue Bezeichnung „Kraftfahrkorps" dokumentierte die steigende Zahl der Motorradfahrer im Korps und hatte eine einladende Signalwirkung an die Mitglieder der parallel existierenden Motorstürme der SA und SS. Darüber hinaus stand der Begriff „Kraftfahrt“ dem NS-

20 Vgl. Oppermann: Unter den Sturmstandern, S. 26.

21 Georg von Walthausen, geb. 1895, Freikorps Epp, ab 1920 in der Kraftfahrzeugbranche tätig, Gruppenstaffelführer, 1934 Führer der Motorbrigade Ostpreußen, NSKK-Gruppenführer, schied 1936 aus dem NSKK aus und war bis April 1938 Betriebsführer der Büssing NAG AG; vgl. Der Großdeutsche Reichstag, IV. Wahlperiode, Berlin 1938, S. 443.

22 Vgl. G. L.Wagener: Warum sollte ich verschweigen, S. 501, 506, StadtA Hannover; Pflichtappell des NSKK der NSDAP Gruppe Hochland am 19. 7. 1932, StA München, Pol. Dir. München 6835.

23 Vgl. Oppermann: Unter den Sturmstandern, S. 27.

24 Schreiben Hühnleins an Kraus vom 10. 4. 1931, StA München, NSDAP 1305. 
Sprachstil näher als der mit snobistischen Anklängen behaftete Begriff „Automobil“. Der nationalsozialistische Motorisierungsjargon beinhaltete in erster Linie deutsche "Kraft"-Begriffe, die als Propagandaschlagworte eingesetzt werden konnten: „Kraftfahrt“, „Kraftwagen“, „Kraftstoff“. Die Bezeichnung „Automobil“" wurde jedoch nicht aus dem Wortschatz getilgt, sondern auch in den Jahren des „Dritten Reiches“ weiterhin verwendet. 25

Wenige Tage nach der Namensänderung erschienen am 1. Mai 1931 die Satzungen des NSKK, die sich in einzelnen Punkten von der Satzung des NSAK und den Richtlinien zum Ausbau unterschieden. Definiert als „Wegbereiter für die Aufstellung der Motorstürme und -staffeln unserer Sturmabteilungen" strebte die OSAF nunmehr eine engere Bindung des Korps an die SA an. Diese Bindung sollte auch über die Mitgliedschaft erfolgen.

\section{Zahl und Zusammensetzung der Mitglieder}

Nach Angaben der Monatsblätter hatte das NSKK im Dezember 193110000 Mitglieder. ${ }^{26}$ Die "meisten“ von ihnen gehörten, so die offizielle Berichterstattung des Korps, außerdem der Motor-SA und -SS an. ${ }^{27}$ Der von der SA-Führung gewünschte Idealzustand im Verhältnis zwischen Korps und Motorstürmen wäre erreicht worden, wenn jedes Mitglied des Kraftfahrkorps auch Mitglied in der Motor-SA gewesen wäre und umgekehrt. Doch die geforderte Kongruenz trat nicht ein.

Besonders die Besitzer teurer Autos und die älteren Kraftfahrer dürften auf die Aufforderung zur Mitgliedschaft in der Motor-SA zurückhaltend reagiert haben. Die Kriterien für die Aufnahme in einen Motorsturm der SA und SS schlossen von vornherein Männer aus, die im fortgeschrittenen Alter standen oder denen es an körperlicher Fitness mangelte. ${ }^{28}$ Der proletenhafte Ruf der SA, die geforderte aktive Dienstausübung und der Unwille, sich von der SA vereinnahmen zu lassen, sind weitere mögliche Gründe der Verweigerung. Auf Seiten der Motor-SA-Männer wirkte sich die doppelte Beitragszahlung trotz 50\%iger Ermäßigung hemmend auf den Eintritt ins NSKK aus. Möglicherweise fanden die SA-Männer neben dem wenig attraktiven Serviceangebot des Korps auch schwerer Zugang zu den Geselligkeitsformen der Korpsmitglieder. Die Erinnerungen des ehemaligen

25 Beispiele hierfür sind „Der Deutsche Automobil-Club“ und die klare Anweisung der Parteikanzlei der NSDAP von 1938, den Begriff „Kraftfahrbahnen“ in Gesetzen und Verordnungen gegen die geläufigere Bezeichnung „Reichsautobahnen“ auszutauschen; vgl. Drittes Gesetz zur Änderung des Gesetzes über die Errichtung eines Unternehmens ,Reichsautobahnen' von 1938, in: Heiber (Bearb.): Akten der Partei-Kanzlei der NSDAP, Teil II, Regestnr. 31751. Zum nationalsozialistischen Motorisierungsjargon vgl. auch S. 168 dieser Arbeit.

26 Vgl. Monatsblätter des Nationalsozialistischen Kraftfahr-Korps und der Motorstürme und -staffeln der SA und SS, H. 1 vom Dezember 1931.

27 Vgl. ebenda. Es besteht Zweifel an dieser Aussage, wenn man die Mitgliedersituation z.B. in Meiningen betrachtet. Von den 32 Mitgliedern der Motor-SA waren im Juni 1932 lediglich 10 SA-Männer zugleich NSKK-Mitglieder; vgl. Die Meininger Motor-SA 1931 bis 1933 (Masch. Manuskript), IfZ MS 603.

28 Vgl. Satzungen, $§ 7$, Pflichten des Mitglieds, in: Oppermann: Unter den Sturmstandern, S. 31 . 
NSKK-Obergruppenführers Georg Wagener bestätigen die gesellschaftliche Kluft zwischen den Formationen. Nach seinen Worten waren die Anfänge des NSKK am „Biertisch“ zu finden. Die älteren und bequemeren Kraftfahrer gaben dem Eintritt ins NSKK den Vorzug, so Wagener, weil es dort gemütlicher zuging, weil sie dort als gesetzte Bürger mit anderen gesetzten Bürgern Umgang pflegten: kurz, weil sie das NSKK für einen „zeitgemäß braungefärbten Automobilklub“ hielten. ${ }^{29}$ Die Motor-SA hingegen empfand eine gewisse Abneigung gegen die "Vereinsmeierei“ des NSKK und die dort dominierenden „spießbürgerlichen“ Kreise. ${ }^{30}$ Diese Animositäten zwischen den Mitgliedern des NS-Kraftfahrkorps und der Motor-SA traten von Anbeginn auf, sie führten aber erst im Laufe der Fusion beider Formationen $1934 \mathrm{zu}$ Problemen. ${ }^{31}$ Mancherorts ergänzten sich Kraftfahrkorps und Motor-SA aber auch. Falls Fahrlehrer einer NSKK-Einheit auch der Motor-SA als Mitglieder angehörten, ermöglichte dies den SA-Männern im Idealfall eine kostenlose Fahrausbildung. ${ }^{32}$ Im Gegenzug durften NSKK-Mitglieder von den SA-Männern Hilfe bei der Wartung ihrer Wagen erwarten. ${ }^{33}$

Gemäß den Satzungen vom 1. Mai 1931 richtete sich die Werbung des NSKK nicht mehr nur an die Fahrzeughalter unter den NSDAP-Mitgliedern und Parteifreunden ${ }^{34}$, sondern auch an „Nur“-Führerscheininhaber. Ob sich dadurch die Zahl der Mitglieder erheblich steigern ließ, ist unwahrscheinlich, denn der Anreiz, sich dem Korps anzuschließen und Beiträge zu zahlen, dürfte für Personen ohne Kraftfahrzeug gering gewesen sein. Es ist wahrscheinlicher, dass die Mitgliedersteigerung zwischen 1930 und 1933 auf die verstärkten Werbemaßnahmen unter den Fahrzeugbesitzern der NSDAP und auf die gezielte Aufforderung an die Motor-SA-Männer zurückzuführen war.

Die Mitgliedsbeiträge blieben von den Anfängen des NSAK bis 1933 weitgehend konstant. Der Jahresbeitrag für Motorrad- und Lkw-Besitzer belief sich auf $8 \mathrm{RM}$, für Kleinpersonenwagen bis $1000 \mathrm{ccm}$ betrug er $12 \mathrm{RM}$ und für andere Personenkraftwagen $20 \mathrm{RM}$. Dies lag unter den üblichen Beitragssätzen der herkömmlichen Automobilclubs. ${ }^{35}$ Fördernde Mitglieder, zu denen auch Kraftfahre-

29 Vgl. G. L. Wagener: Warum sollte ich verschweigen, S. 555, StadtA Hannover.

30 Vgl. ebenda, S. 501, 505. Vgl. dazu auch die Ausführungen Reichardts zum antibürgerlichen Reflex der SA; ders.: Faschistische Kampfbünde, S. $463 \mathrm{ff}$.

31 Zum Zusammenschluss der Motorformationen vgl. S. $72 \mathrm{f}$. dieser Arbeit.

32 Vgl. Völkischer Beobachter vom 17. 2. 1931: „NSAK“.

33 Vgl. Kühnel: Hans Schemm, S. 403, Anmerkung 141.

34 Es kursierten widersprüchliche Angaben zur Mitgliedschaft. In $₫ 2$ der Satzungen wurden neben den Parteigenosssen auch Parteifreunde genannt. In anderen Publikationen wurde die Mitgliedschaft im NSKK an die Mitgliedschaft in der NSDAP gebunden; vgl. Völkischer Beobachter vom 26./27.6. 1932: „Was will das Nationalsozialistische Kraftfahrkorps?" In einem persönlichen Schreiben von Kraus an den Motorsturmführer Fetzer vom 2. 2. 1932 erklärte Kraus, dass das NSKK nur "männliche Parteigenossen“ aufnehme; BArch NS 24/110.

35 Vgl. Oppermann: Unter den Sturmstandern, S. 30; NSKK-Korpsführung vom 23. 6. 1932, betr. Beiträge, StA München, Pol. Dir. München 6835. Die üblichen Beitragssätze der anderen Automobilclubs bewegten sich bei 30 RM für Autos und 20 RM für Motorräder im Jahr. 
rinnen zählten, konnten die außerordentliche Mitgliedschaft erwerben. ${ }^{36}$ Sie bezahlten einen Mindestbeitrag von $2 \mathrm{RM}$ pro Monat, also den nicht geringen Betrag von $24 \mathrm{RM}$ im Jahr. Dafür erhielten sie das Presseorgan des Korps und waren zum verbilligten Bezug von Grenzpassierscheinen ${ }^{37}$ befugt.

Von Anfang an war das Streben der Korpsführung erkennbar, innerhalb des NS-Kraftfahrkorps eine eigene Gruppenidentität zu entwickeln. Neben gemeinsamen Übungen und "Motortreffen" geschah dies auch durch sichtbare Zeichen der Zusammengehörigkeit. Die Mitglieder des NSKK trugen das Hoheitszeichen des Korps am Zivilanzug und bei geschlossenem Auftreten eine braune Sportmütze. Mitglieder der Motor-SA traten in ihrem SA-Dienstanzug auf. Auf dem Kühler der Autos wurde eine Korpsplakette befestigt und bei Dienstfahrten ein Wimpel am Wagen angebracht. ${ }^{38}$ Das NSKK verfügte seit seiner Gründung über eigene Presseorgane, die korpsinterne Mitteilungen an die Mitglieder weitergaben. Am 7. Mai 1931 erschien die erste Ausgabe des „Mitteilungsblattes des NSKK“, und im Dezember 1931 brachte der Oppermann-Verlag in Hannover zum ersten Mal die „Monatsblätter des NSKK“ heraus. ${ }^{39}$

Ein Problem, das den Einsatz der nationalsozialistischen Kraftfahrer seit Anbeginn begleitete, war die Frage nach einer ausreichenden Versicherung der Fahrzeuge und Insassen. Während der Dienstfahrt war der Fahrer in puncto Personenschäden über die Hilfskasse der NSDAP versichert. Für Unfallschäden am Fahrzeug haftete der Fahrzeughalter jedoch selbst. ${ }^{40}$ Mit der aktiven Teilnahme an SAAufgaben war für den Fahrer, der sich und sein Fahrzeug in den Dienst der Bewegung stellte, folglich ein hohes persönliches und finanzielles Risiko verbunden, das in keiner Relation zu den wenigen praktischen Vorteilen einer Mitgliedschaft im Nationalsozialistischen Kraftfahrkorps stand. Wer dem NSKK und der Motor-SA vor 1933 im aktiven Sinne, also nicht als förderndes Mitglied oder SA-Reserve, angehörte, bewies damit eine hohes $\mathrm{Maß}$ an persönlicher Einsatzbereitschaft und Entschlossenheit zur tatkräftigen Mitwirkung am Aufstieg der Bewegung.

36 Vgl. Völkischer Beobachter vom 26./27.6. 1932: „Was will das Nationalsozialistische Kraftfahrkorps?“. Dem Aufnahmegesuch einer Frau Dr. V., die durch freiwillige Beiträge den Ausbau des Korps vorantreiben wollte, wurde im Januar 1932 stattgegeben; Schreiben des Bereichführers des NSKK Berlin/Brandenburg vom 2. 1. 1932, BArch NS 24/110.

37 Für den Grenzübertritt mit dem Auto war der Erwerb von Grenzpassierscheinen oder Triptyks (auch Triptiks) erforderlich, die eine Bürgschaft gegenüber den ausländischen Zollbehörden enthielten. Das Monopol auf die Vergabe hatten der AvD, der ADAC und der DTC. Auslandsreisen mit dem Auto waren somit an die Mitgliedschaft des Automobilbesitzers in einem der drei Verbände oder angegliederten Körperschaften gebunden; vgl. die Kritik des technischen Leiters des NSKK am Monopol der Clubs in einem Exposé über Triptyks, BArch, NS 24/110.

38 Vgl. Oppermann: Unter den Sturmstandern, S. 30.

39 Vgl. ebenda, S. 32 und Monatsblätter des NSKK vom Dezember 1931.

$40 \mathrm{Im}$ Parteidienst waren die $\mathrm{Pkw}$-Fahrer über die Hilfskasse der NSDAP versichert. Die Beiträge dazu waren im Korpsbeitrag enthalten. Motorradfahrer hatten für die Versicherung einen erhöhten Beitrag zur Hilfskasse zu leisten. Der Schutz erstreckte sich nur auf Personenschäden. Haftpflicht und Kasko mussten von den einzelnen Fahrern selbst abgeschlossen werden. Das Korps bot nur eine Versicherungsvermittlung an; vgl. Monatsblätter des NSKK vom Dezember 1931: „Versicherung“. 
Das NSKK - ein politischer Automobilclub?

Die Automobil- und Motorradbesitzer, die auf wirtschaftliche Vergünstigungen, Beratung, Touristik, Motorsport oder Förderung der Kraftfahrt im Allgemeinen Wert legten, waren zumeist Mitglied in einem der folgenden Automobilclubs: Allgemeiner Deutscher Automobilclub (ADAC, 1931: 132000 Mitglieder), Automobilclub von Deutschland (AvD, 1933: 16000 Mitglieder) ${ }^{41}$, Deutscher Motorradfahrer-Verband (DMV, 1930: 25000 Mitglieder), Deutscher Touring Club (DTC, 1930: 32000 Mitglieder). Eine der wichtigsten Dienstleistungen der Clubs war das Angebot an so genannten Triptyks. Dieser Grenzpassierschein machte dem Kraftfahrer den Grenzübertritt möglich, ohne den vom Reiseland festgesetzten Zoll entrichten zu müssen. 42

Viele nationalsozialistische Kraftfahrer, die Mitglieder in den herkömmlichen Automobilclubs waren, dürfte die Doppelmitgliedschaft und die damit verbundenen doppelten Beitragszahlungen vom Eintritt in das Korps abgehalten haben. ${ }^{43}$ Kritik richtete Kraus deshalb in erster Linie an Parteigenossen, die bisher nicht Mitglied im NSKK waren:

„Vor der Pflege des Sports und der Touristik kommt der Kampf um die Freiheit des Volkes und der Wirtschaft. Das NSKK kann es nicht dulden, daß ein Parteigenosse Mitglied eines Klubs bleibt, seinen Beitritt zum NSKK aber unterläßt. Wir brauchen jedes Fahrzeug und jeden Führerschein. “44

Die Propagandisten des NSKK stießen jedoch bei ihren Werbebemühungen schnell an die Grenzen der politischen Mobilisierbarkeit von Automobilbesitzern, die sich eben gerade aus wirtschaftlichen und touristischen Gründen den Clubs angeschlossen hatten.

Um dies zu ändern, rief der technische Leiter Kraus in einem Schreiben an seinen Chef Hühnlein im April 1931 dazu auf, den Mitgliedern mehr „Klubvorteile“, wie Empfehlungen von Hotels und Werkstätten mit Rabatt, vertragliche Vereinbarungen mit Betriebsstofffirmen, Beschaffung von Grenzübertrittskarten, Rechtsschutz und Versicherung zu offerieren. ${ }^{45}$ Das Ziel, die Serviceleistungen zu verbessern, dürfte auch der Grund dafür sein, warum die Korpsführung zuerst

41 Der AvD hatte 193316211 ordentliche und außerordentliche Mitglieder. Dem Stammclub gehörten 55 Automobil-Clubs an. Ferner waren dem AvD auch Verbände angeschlossen deren Mitglieder in der genannten Zahl nicht mitgerechnet sind: Der RDA, der AeroClub, die Automobil- und Flugtechnische Gesellschaft, der Deutsche Motorradfahrerverband, der Mitteleuropäische Motorwagen-Verein und andere Kraftfahrvereinigungen mit rund 80000 Mitgliedern; vgl. Fritsch: Der Einfluß des AvD, S. 100-105.

42 Durch Ausstellung des Triptyks übernahm der inländische Club gegenüber dem ausländischen und seiner Zollverwaltung die Bürgschaft für die Wiedereinfuhr des Fahrzeugs; vgl. Der Motorsportler. Verbandsorgan des Allgemeinen Motorsport Verbandes (AMV) vom 18. 3. 1932: "Wie das Triptyk entstand“.

$43 \mathrm{Da}$ der Fahrer in der Beitrittserklärung angeben musste, ob er bereits Mitglied in einem Automobilclub war, wusste die Korpsführung um das „Problem“ der Doppelmitgliedschaft; vgl. Beitrittserklärung für das NSKK (Formular ohne Datum), StA München, Pol. Dir. München 6835.

44 Monatsblätter des NSKK vom Juli 1932: „Die Automobilclubs und das NSKK“.

45 Schreiben von Kraus an Hühnlein vom 5. 4. 1931, StA München, NSDAP 1305. 
Mitglied im Nationalen Deutschen Automobilclub wurde und im Sommer 1932 mit dem Deutschen Touring Club ein Abkommen traf, das die verbilligte Abgabe von Triptyks und Grenzpapieren ermöglichte. ${ }^{46}$

Kommunistische Kreise sahen in der Aufstellung eines Automobilkorps, dann Kraftfahrkorps, den Beweis für die großbürgerliche und kapitalistische Trägerschicht der NSDAP. Die Existenz des Automobilkorps sei bezeichnend für die Mitgliederstruktur in der Hitler-Partei, bei der es sich ihrer Meinung nach um eine „Bonzen-Partei“ handelte. ${ }^{47}$ Die NSDAP in der Öffentlichkeit als Partei des Großkapitals auszuweisen, entsprach den Propagandamethoden der sozialdemokratischen und kommunistischen Parteiführung. ${ }^{48}$ Die Sozialstruktur des NSKK, dessen Mitglieder zumindest in der Anfangszeit dem oberen Mittelstand angehörten, wie es der Besitz eines Autos bezeugt, ${ }^{49}$ konnte indes nicht als repräsentativ für die allgemeine Zusammensetzung der NSDAP gelten. ${ }^{50}$ Dennoch musste die Parteileitung der NSDAP sich vor allem aus den Reihen der SA den Vorwurf gefallen lassen, die Parteifunktionäre pflegten einen zu hohen Lebensstandard. Dies wurde besonders von der Berliner SA unter Führung des OSAF-Stellvertreters Ost, Walter Stennes, kritisiert. Auf einem Flugblatt der SA vom Mai 1931 war zu lesen:

„Wir schieben ja so gern Kohldampf, damit es unseren lieben Führern mit ihren 2- bis 5000 Mk. Monatseinkommen recht wohl ergehe. Hocherfreut waren wir auch, als wir hörten, daß sich unser Adolf Hitler auf der Berliner Automobilausstellung einen großen Mercedeswagen für RM 40000 gekauft hat ${ }^{\text {} 51}$

46 Monatsblätter des NSKK vom Juli 1932: „Beschaffung von Triptiks“. Vgl. zur korporativen Mitgliedschaft im NDA auch die Erinnerungen Otto Wageners: Hitler aus nächster Nähe, S. $66 \mathrm{f}$.

47 Presseausschnitt aus einer kommunistischen Zeitung um 1930 mit dem Titel: „Faschistisch-nationalsozialistische Verbrüderung", StA Leipzig, PPV 4255 (NDA).

48 Vgl. Pyta: Gegen Hitler und für die Republik, S. 58.

49 Darauf weisen die sechs noch vorhandenen Mitgliedskarten im Bereich NSKK-Ost aus dem Jahre 1931 hin. Darunter waren ein Geschäftsführer, ein Kaufmann, ein Arzt und ein Beamter. Sie gehörten der NSDAP an und verfügten über Führerscheine und Fahrzeuge; BLHA Potsdam, Rep. 61 C Nr. 373.

50 Die NSDAP war keine Partei der Oberschicht, sondern in erster Linie eine Mittelschichtspartei; vgl. die soziale Zusammensetzung der NSDAP-Mitglieder zwischen dem 15. 9. 1930 und dem 30. 1. 1933: 32,5\% Arbeiter, 20,6\% Angestellte, 17,3\% Selbständige, 6,5\% Beamte, $12,5 \%$ Bauern, 3,7\% Sonstige; vgl. Jamin: Zwischen den Klassen, Tab. IV3-2 (Parteistatistik von 1935), S. 247. Absolut gesehen fällt die Zahl der Arbeiter im internen Mitgliedervergleich der NSDAP durchaus ins Gewicht. In Relation zur Beschäftigungsstruktur im Deutschen Reich waren Arbeiter, die rund 55\% der Bevölkerung ausmachten, in der NSDAP unterrepräsentiert; vgl. ebenda, S. 245. Einschränkend muss gesagt werden, dass die Aussagen, die auf der Parteistatistik der NSDAP von 1935 beruhen, eine Tendenz wiedergeben, nicht aber empirisch belegtes Datenmaterial, da hier nur die Mitglieder erfasst wurden, die 1935 noch Mitglied waren, und nicht diejenigen, die zwischen 1930 und 1933 wieder ausgeschieden waren. Der Anteil des gehobenen Mittelstandes in der NSDAP erhöhte sich in der „Kampfzeit“ kontinuierlich. Die Quote übertraf 1932 den Reichsdurchschnitt; vgl. Kater: Ansätze einer Soziologie der SA bis zur RöhmKrise, S. 806. Von der durchschnittlichen sozialen Zusammensetzung gesehen war die NSDAP eine Mittelstandsbewegung. Um jedoch zu betonen, dass die NSDAP alle sozialen Schichten anzusprechen vermochte, ist die Bezeichnung „Volkspartei des Protests" angemessener; vgl. Wirsching: Die Weimarer Republik in ihrer inneren Entwicklung, S. 103.

51 Zit. nach Höhne: Der Orden unter dem Totenkopf, S. 64. 
In der Anschaffung und Verwendung von Autos wurde demnach nicht immer die Notwendigkeit einer Mobilitätssteigerung gesehen, sondern auch die luxuriöse Zurschaustellung von Macht und Geld. Hitlers Vorliebe für Mercedes-Benz-Limousinen verstärkte dieses innerparteiliche Misstrauen zusätzlich.

\section{Die Gliederung des NSKK}

Geographisch war das NSKK der Gliederung der SA angepasst. Durch das starke Wachstum und die häufige Neugliederung der Gebiete traten sowohl bei der Motor-SA als auch beim NSKK zahlreiche organisatorische Veränderungen auf. Auf der Ebene der inzwischen auf 18 angewachsenen SA-Gruppen agierten die NSKK-Landesführer. Bereichführer waren für den Bereich der Untergruppe, Bezirksführer und Korpswarte für die kleineren Gebiete zuständig. Die Korpswarte hatten die Aufgabe, in allen NSDAP-Ortsgruppen nationalsozialistische Kraftfahrer für das NSKK zu werben. ${ }^{52}$

Die Führung des NSKK nahm durch die Errichtung eines festen Stabes und die Anstellung von hauptamtlichen Mitarbeitern Gestalt an. Die Verantwortung lag im August 1932 in den Händen des stellvertretenden Korpsführers und Chefs des Kraftfahrwesens der SA, SA-Gruppenführer Hühnlein. Zum Korpsstab zählte der Stabsführer Oberführer Oldenbourg und der Leiter der Sonderabteilungen Wehr, Wirtschaft und Presse, Theodor Oppermann, der zugleich Verleger und Schriftleiter der Monatsblätter war. Die technische Beratung übernahm Ingenieur Erwin Kraus in Stuttgart. Daneben existierten die Ressorts Recht und Versicherungsvermittlung. Zum Ehrenführer des Kraftfahrkorps hatte die OSAF den langjährigen militärischen Vorgesetzten Hühnleins, General Ritter von Epp, ernannt. ${ }^{53}$

\section{Die Motor-SA 1931-1933}

Am 1. April 1930 erließ die OSAF nicht nur die Anordnung zur Gründung eines NS-Automobilkorps, sondern auch einen Befehl, der den vereinzelt existierenden Motorformationen der SA eine Organisationsstruktur gab. ${ }^{54}$ Die Anweisung legte fest, dass jedem SA-Sturm ein Motortrupp beigeordnet werden sollte, in dem alle zum Sturm gehörenden SA-Männer zusammengeschlossen sind, die ein Motorrad oder einen kleinen Pkw (DKW, Hanomag, Opel 4/16, Dixi) besitzen. Motorräder

52 Krenzlin: Das NSKK, S. $11 \mathrm{f}$.

53 Vgl. Monatsblätter des NSKK vom Juli 1932: „NSKK“ und die Sonderstellen der Korpsführung, abgedruckt in: Monatsblätter des NSKK vom August 1932. Hühnlein war nach dem Ersten Weltkrieg im Freikorps Epp am Sturz der bayerischen Räterepublik beteiligt. 1922 wurde er von General Ritter von Epp, dem Führer des Infanterieregiments VII, als 1. Generalstabsoffizier in seinen Stab berufen; vgl. Der NSKK-Mann 13. 9. 1941: „Soldat. Zum 60. Geburtstag unseres Korpsführers“.

54 In vielen größeren Orten, z.B. Hamburg, existierten 1929 bereits SA-Motortrupps; vgl. Krause: Hamburg wird braun, S. 145. Im gleichen Jahr motorisierte sich auch die SA-Standarte I Berlin in einer Stärke von 70 Fahrzeugen und 95 Fahrern; vgl. Schreiben von Rolf Hilgert an den Inspekteur des Kraftfahrwesens der NSDAP vom 20.7.1932 (Abschrift), BArch NS 24/242. 1929 waren auch erste Anfänge in Dresden feststellbar; vgl. Lein: Die Geschichte der Sächsischen Motor-SA, S. 47. 
waren in uneingeschränkter Anzahl zugelassen, während die Zahl der Pkw auf zwei je Sturm beschränkt wurde. Innerhalb einer Standarte wurden die Motortrupps zu einem Motorsturm vereinigt. Der erste Motorsturm in München war der 1930 gegründete Motorsturm „München Oberbayern“. Er war der SA-Leibstandarte angegliedert. 55

Der Sturmführer sollte neben Führungsqualitäten auch über technische Kenntnisse verfügen und ein eigenes Motorrad oder einen Kraftwagen besitzen. Zum Stab einer SA-Standarte trat ein Motorsturmführer, zum Stab des SA-Brigadeführers bzw. -Oberführers ein Motor-Staffelführer. Anfänglich unterstanden die Motortrupps für den allgemeinen Dienst ihrem SA-Sturmführer. Für Fahrübungen und Nachrichtenübungen konnte der Motorsturmführer seinen ganzen Motorsturm zusammenziehen. Die SA-Männer der Motor-Stürme und Motor-Staffeln trugen anstelle der Sturm- bzw. Staffelnummern im rechten Kragenspiegel ein gesticktes Rad.

Die Aktivitäten der Motor-SA bestanden seit ihrer Gründung in der Beförderung der Versammlungsredner und SA-Führer sowie im Transport von SA-Mannschaften und in der Übermittlung von Nachrichten. ${ }^{56}$ Unter Ausnutzung der von der motorisierten Fortbewegung ausgehenden Mobilität waren der "fliegende“ Versammlungsschutz, Propagandafahrten aufs Land und das Plakatekleben bevorzugte Aufgabenfelder der Motorstürmer. ${ }^{57}$

Als Ernst Röhm am 5. Januar 1931 das Amt des Stabschefs der SA übernahm, traf er Maßnahmen zur Umstrukturierung der SA. Sein Ziel war es, eine mitgliederstarke Volksmiliz zu schaffen. Zu den organisatorischen Maßnahmen zählte auch der Ausbau der bereits vorhandenen Motorformationen. Röhm erließ am 15. Mai 1931 eine neue Anweisung zur Aufstellung von SA- und SS-Motorstürmen und -Motorstaffeln. ${ }^{58}$ Der Motortrupp Ravensburg z. B., der bisher an den SA-Sturm 2/ II Ulm angeschlossen war, wurde $1931 \mathrm{zu}$ einem selbständigen Sturm ausgebaut. ${ }^{59}$ An das NSKK, das als Sammelbecken der nationalsozialistischen Kraftfahrer diente, erging die Aufforderung, seine aktiven Mitglieder für die Arbeit der Motor-SA zur Verfügung zu stellen. Um eine höhere Bereitschaft und Mobilität der Motor-SA zu erreichen, wurde die Organisation in Motorscharen, Motortrupps, Motorstürme und Motorstaffeln gegliedert. Der Motorsturm, zu diesem Zeitpunkt größter eigenständiger Verband der Motor-SA, unterstand dem

55 Vgl. Mitteilungsblatt Kreis München der NSDAP vom 14. 1. 1937: „Münchens Motorstandarte M 86“, StA München, NSDAP 1321. Der Sturm wurde von dem Gewehrfabrikanten Oberhammer ins Leben gerufen; vgl. Lageberichte der Polizeidirektion München vom 24. 10. 1930, Nr. 94, S.9, StA Amberg, Regierung der Oberpfalz, KdI, Abgabe 1949ff. Nr. 13907. Vgl. zur Entwicklung der Motorstürme in München Rösch: Die Münchner NSDAP, S. 248, $251 \mathrm{ff}$.

56 Vgl. Der Bayerische Staatsminister des Innern über die SA 1931, in: Bericht des bayerischen Staatsministers des Innern: „Die Nationalsozialistische Arbeiterpartei“, S. 12 ff., BArch NS 26/317.

57 Vgl. Werner: SA und NSDAP, S. 555.

58 „Anweisung für die Aufstellung von SA- und SS-Motorstürmen und -staffeln“ vom 15. 5. 1931, abgdruckt in: Oppermann: Unter den Sturmstandern, S. $33 \mathrm{ff}$.

59 Entstehungsgeschichte der NSKK-Motorstandarte 156 Konstanz (Heft), o. J., BArch NS $24 / 555$. 
örtlichen SA-Sturmbann. Das Ziel, dass jeder SA-Sturmbann einen eigenen Motorsturm unterhalten sollte, war eine schwer durchzusetzende Forderung. Kein SA-Sturmführer wollte auf seine Kraftfahrzeugbesitzer verzichten, da seine Einheit dadurch Mobilität einbüßen würde. 60

Die dem Motorsturm übergeordneten Führer befehligten keine eigene Einheit, sondern wachten über die Entwicklung des Kraftfahrwesens in ihrem Gebiet. Dem Stab der SA-Standarte war ein Motor-Staffelführer zugeteilt, der SA-Brigade stand ein Oberstaffelführer zur Seite, beim Stab der SA-Gruppe gab es den Gruppenstaffelführer, und die OSAF unterhielt einen Inspekteur der SA- und SS-Motorstürme und Motorstaffeln.61 Im August 1932 waren auf der Ebene der vier SAInspekteure Ost, Nord, West und Süd Kraftfahrinspekteure tätig. Das Amt des Inspekteurs der SA- und SS-Motorstürme hatte der stellvertretende Korpsführer, SA-Gruppenführer Adolf Hühnlein, übernommen. Er war für eine einheitliche kraftfahrtechnische Ausbildung verantwortlich und überwachte den Dienstbetrieb der Stürme. Außerdem hatte er als Chef des Kraftfahrwesens die Aufsicht über die parteieigenen Kraftwagen der SA.62

Die Motor-SS wurde ebenfalls vom Inspekteur der SA- und SS-Motorstürme beaufsichtigt. Die separate Anweisung des Reichsführers-SS Heinrich Himmler vom 21. März 1931 über Ausbildung und Verwendung der SS-Motorstürme zeigt jedoch, dass die SS in der Frage der Motorisierung, wie auch in anderen Bereichen, um Eigenständigkeit bemüht war. Himmler kündigte an, jeden SS-Sturmbann zu motorisieren, indem unter den SS-Männern für den Eintritt in die SS-Motorstürme geworben werden sollte. ${ }^{63}$ Die Ausbildung, der Aufbau und der Zweck der SS-Motorstürme entsprachen den SA-Motorstürmen, allerdings mit dem Unterschied, dass die Motor-SS ausschließlich der SS-Führung zur Verfügung stand. Die Einsetzung eines eigenen Reichsstaffelführers der SS, Major a. D. Häfner64, der bei der Inspektion der Motorstürme für Fragen der SS-Motorstürme zuständig war und bei Abwesenheit des Inspekteurs Hühnlein für die gesamte MotorSA die Verantwortung trug, verdeutlicht die Teilautonomie. ${ }^{65}$

60 G. L. Wagener: Warum sollte ich verschweigen, S. 500, 523, StadtA Hannover.

61 Vgl. ebenda, S. 498. Die Motorstaffel der SA-Standarte 124 war 1932 unterteilt in Motorstürme 1-7/124; vgl. Entstehungsgeschichte der NSKK-Motorstandarte 156 Konstanz (Heft), o. J., BArch NS 24/555.

$62 \mathrm{Vgl}$. OSAF-Dienstanweisung an den Inspekteur der SA- und SS-Motorstürme und -staffeln vom 31. 7. 1931, BayHStA München, MInn 81625.

$63 \mathrm{Vgl}$. Vorläufige Anweisung für die Ergänzung, Ausbildung und Verwendung der SS-Motorstürme vom 21. 3. 1931, ebenda.

64 Major a. D. Konrad Häfner gründete den ersten eigenen SS-Motorsturm in München, bestehend aus 25 Mann, drei Autos und zehn Motorrädern; vgl. Lageberichte der Polizeidirektion München vom 25. 1. 1931, StA Amberg, Regierung der Oberpfalz, KdI, Abgabe 1949 ff. Nr. 13907.

65 Vgl. OSAF-Dienstanweisung an den Inspekteur der SA- und SS-Motorstürme und -staffeln vom 31.7. 1931, BayHStA München, MInn 81625. NSKK-Obergruppenführer G. L. Wagener erklärte nach dem Krieg, dass das elitäre Denken der SS bereits in der Frühzeit eine wirkliche Unterstellung unter die Inspektion der SA- und SS-Motorstürme unmöglich gemacht habe; vgl. ders.: Warum sollte ich verschweigen, S. 499, StadtA Hannover. 


\section{Der Zustrom zu den Motorstürmen}

Die Bemühungen des neuen SA-Stabschefs Röhm, einen mitgliederstarken Wehrverband zu schaffen, trugen bald Früchte. Im Oktober 1931 zählte die SA rund 2000 Stürme und 100 Motorstürme. ${ }^{66}$ Der enorme Mitgliederzuwachs der SA im Laufe des Jahres 1932 wirkte sich auch auf die Motor-SA aus: Im Juli 1932 bestanden 588 Motorstürme im Reich, einen Monat später waren es bereits 680 Motorstürme. Die Stärke der Motor-SA wurde im August 1932 mit 26105 Angehörigen angegeben. ${ }^{67}$

Untersuchungen zur Sozialstruktur der SA kommen zu dem Ergebnis, dass die Mehrheit der Mitglieder aus Arbeitern (50-55\%) und Angestellten bestand. ${ }^{68}$ Das zweite charakteristische Merkmal der SA war das junge Durchschnittsalter ihrer Mitglieder: Der überwiegende Teil der SA-Mitglieder war unter $30 \mathrm{Jahre}$ alt. ${ }^{69}$

Die Chronisten des NSKK und der Motor-SA, allen voran Theodor Oppermann, kreierten das Bild vom arbeits- und mittellosen SA-Fahrer, der den "letzten Pfennig" seiner Unterstützung in die Maschine steckte, um der Bewegung zu helfen. ${ }^{70} \mathrm{Da}$ jedoch der "letzte Pfennig“ nicht ausreichend war, um den Anschaffungspreis eines Fahrzeugs zu bezahlen und die Unterhaltskosten zu tragen, legt der Umstand, dass die Motor-SA-Angehörigen ihre Motorräder und Autos selbst stellten bzw. Fahrzeuge aus geschäftlichem Besitz einbrachten, die Vermutung nahe, dass der durchschnittliche Motor-SA-Mann im Vergleich zur „allgemeinen“ SA älter war und sich beruflich und sozial bereits etabliert hatte. ${ }^{71}$ Einige Stichproben von Motorstürmen bestätigen diese Annahme. Beim Münchner Motortrupp SA Sturmbann I/L waren 1932 nur 3,2\% un- und angelernte Arbeiter, dage-

66 Vgl. Krause: Hamburg wird braun, S. 243.

$67 \mathrm{Vgl}$. Werner: SA und NSDAP, S. $551 \mathrm{f}$. Zusätzlich zur Motor-SA gab es 445279 nicht extra bezeichnete SA-Männer (allgemeine SA) und 23853 SS-Männer. Die Motor-SS-Männer sind wahrscheinlich in der Gesamtzahl der SS enthalten.

$68 \mathrm{Vgl}$. Jamin: Zwischen den Klassen, S. 371. Die soziale Zusammensetzung der SA wird von Historikern immer noch kontrovers diskutiert. Dies ist auf die unterschiedliche Kategorienbildung und den regional ungleichen Arbeiteranteil in Deutschland zurückzuführen. Michael Kater kam zu dem Schluss, dass die Stamm-SA wie die NSDAP 1929 bis 1933 eine hauptsächlich von Kleinbürgern und nicht von Arbeitern beherrschte Sozialstruktur aufwies; ders.: Ansätze einer Soziologie der SA bis zur Röhm-Krise, S. $802 \mathrm{f}$. Kater wandte dabei eine extrem enge Definition des Arbeiters an. Facharbeiter und untere Handwerksgesellen rechnete er zum Mittelstand; vgl. die Kritik von Jamin: Zwischen den Klassen, S. $28 \mathrm{ff}$. Conan Fischer ging im Gegensatz dazu von einem sehr hohen Arbeiteranteil aus, den er aus Berichten über die hohen Arbeitslosenzahlen in SA-Stürmen ableitete; ders.: Stormtroopers. A social, economic, and ideological analysis. Richard Bessel weist für ländliche Gebiete in Schlesien und den Regierungsbezirken Königsberg und Allenstein die Bauernschaft als stärkste Gruppe in der SA nach; vgl. ders.: Political Violence, S. $36 \mathrm{f}$.

69 Vgl. Jamin: Zwischen den Klassen, S. 88.

70 Oppermann: Unter den Sturmstandern, S. 41.

71 Auch wenn man vermuten kann, dass viele Motor-SA-Mitglieder Kleinkrafträder fuhren, für die kein Führerschein erforderlich war, verursachten der Unterhalt, eventuelle Reparaturen und vor allem der Treibstoff Sonderkosten, die einfache Arbeiter kaum aufbringen konnten. Die SA gab in den Wahlzeiten 1932 an besonders bedürftige Fahrer Benzingutscheine aus, sie verfügte aber nicht über die Mittel, den Mitgliedern der Motor-SA eine generelle finanzielle Unterstützung zu gewähren. 
gen fast 50\% Handwerker, 25\% Facharbeiter, 14,2\% kleine und mittlere Kaufleute und je 7\% untere Angestellte und akademische Freiberufler eingeschrieben. ${ }^{72}$ In Landkreisen hingegen, in denen die SA einen hohen Mitgliederanteil aus der Unterschicht hatte, wie z. B. in Hessen-Nassau, überwog auch in der MotorSA der Arbeiteranteil. Jedoch war er nicht ganz so hoch wie in der „allgemeinen“ SA, weil einige Mitglieder aus der Mittel- und Oberschicht kamen und dadurch die Mitgliederzusammensetzung heterogener gestalteten. ${ }^{73}$ Auch beim SS-Motorsturm in Wiesbaden M/I/2 stammte die Mehrzahl der Mitglieder aus der Unterschicht. ${ }^{74}$ Doch unterschied sich die Berufsstruktur merklich vom Durchschnitt in der SS oder SA, da dem Motorsturm eine Vielzahl an Mechanikern, Schlossern und Lkw-Fahrern angehörte. Auch ein höherer Altersdurchschnitt lässt sich bei den Mitgliedern von SA-Sonderformationen belegen, die zum Teil aufgrund ihrer Profession oder ihres Fahrzeugbesitzes diese Vereinigung auswählten. ${ }^{75}$

Im Zusammenhang mit der Zusammensetzung der Motor-SA ist außerdem zu betonen, dass die Motorstürme nur teilmotorisiert waren. Nicht alle Motor-SAMänner, die einen Führerschein besaßen, hatten gleichzeitig ein eigenes Fahrzeug. Dies belegt die Mitgliederstruktur der Motor-SA in Meiningen, die auch für andere Motorstürme repräsentativ sein dürfte: Der Motorsturm bestand im Juni 1932 aus 32 Mitgliedern, die insgesamt über acht Pkw und zehn Motorräder verfügten. Daraus folgt, dass knapp die Hälfte der Mitglieder kein eigenes oder kein angemeldetes Fahrzeug hatte. ${ }^{76}$

\section{Die Ausbildung eigener Gruppenidentitäten}

Das SA-Treffen in Braunschweig am 17. und 18. Oktober 1931 markierte den ersten gemeinsamen öffentlichen Auftritt des NSKK und der Motor-SA. Das Datum ging als eigentliche Geburtsstunde der Motor-SA in die NS-Geschichtsbücher ein. ${ }^{77}$ Der Großaufmarsch vor dem „Führer“, verbunden mit dem ersten Reichstreffen des NSKK, zu dem rund 5000 Fahrzeuge zusammengezogen worden sein sollen, stellte auch einen Höhepunkt in der noch jungen Geschichte des Kraftfahrkorps dar. ${ }^{78}$ Öffentliche Auftritte, insbesondere unter den Augen Hitlers, stärkten das Zusammengehörigkeitsgefühl der SA nach innen und demonstrierten Geschlossenheit und Einsatzbereitschaft nach außen.

72 Vgl. Kater: Ansätze einer Soziologie der SA, S. 810.

73 Mühlberger untersuchte in den Landkreisen Witzenhausen und Großalmerode in HessenNassau die Sozialstruktur der SA vor 1933. Er fand heraus, dass auch im Motorsturm V/ 83 mit 56,7\% die Unterschicht die Mehrheit bildete, doch war sie nicht so stark vertreten wie in der allgemeinen SA, wo der Anteil rund $70 \%$ betrug. Problematisch bei der Analyse ist, dass Mühlberger ungelernte Arbeiter genauso wie Handwerker der „lower class“ zurechnet; ders.: Hitler's Followers. Studies in the Sociology of the Nazi Movement, S. 175, 178.

74 Ebenda, S. 196.

75 Ebenda, S. 195, 200.

76 Vgl. Die Meininger Motor-SA 1931 bis 1933 (Masch. Manuskript), IfZ MS 603.

77 Vgl. Lein: Die Geschichte der Sächsischen Motor-SA, S. 47.

78 Vgl. Oppermann: Unter den Sturmstandern, S. $47 \mathrm{ff}$. 
Die Angehörigen der SA- und SS-Motorstürme leisteten regelmäßige „Dienste", die kraftfahrtechnische Übungen und weltanschauliche Unterrichtseinheiten beinhalteten. Am Sonntag stand zumeist der Fahrdienst mit Übungs- oder Propagandafahrten auf dem Programm. 1932 fand zweimal im Monat ein Theorieunterricht statt, in dem Übungsaufgaben wie z. B. der Einsatz der Motorsturm-Formationen bei Verteidigung und Angriff und bei „bolschewistischen Unruhen“ besprochen wurden. Der Ablauf und die Häufigkeit der Sturmabende richteten sich nach dem Entwicklungsstand der Motorstürme und gestalteten sich regional sehr unterschiedlich. Auf dem Dienstplan standen verkehrstechnische Unterweisungen, Kartenlesen, Kleinkaliberschießen, der Aufbau von Musik- und Spielmannszügen, Vorschriften über das Verhalten bei politischen Zusammenstößen sowie weltanschauliche Vorträge. ${ }^{79}$

Wenn von den Vorzügen der Motor-SA gegenüber der „allgemeinen“ SA die Rede war, wurden gemeinhin die Geschwindigkeit, das Überraschungsmoment und die Transportleistung betont. Dies trug dazu bei, dass sich bei den Motorstürmern bereits sehr früh eine spezifische Identität herausbildete. Der Motor-SAMann war nicht „nur“ ein SA-Mann, also ein politischer Kämpfer, sondern darüber hinaus ein „Motorkämpfer“. Hitler wird 1933 mit dem Satz zitiert: „Der Motor-SA Mann muß mit seiner Maschine verwachsen sein wie die Hunnen mit ihren Pferden." 80 Die Macht des Motors potenzierte die ihm zur Verfügung stehende Kampfkraft um ein Vielfaches. Der Einsatz des Fahrzeugs bot dem Motorstürmer außerdem die Möglichkeit, ein besonderes $\mathrm{Maß}$ an Einsatzbereitschaft zu demonstrieren. Das finanzielle Risiko sowie die erhöhte Unfallgefahr in Stresssituationen, die Motorrad-, Auto- oder Lkw-Fahrer eingingen, verstanden die Aktiven als Zeichen ihres großen Opferwillens für die Bewegung. Die Identität des Motorkämpfers wurde durch eigene Motor-SA-Lieder gefördert, die den Abenteuergeist der Mitglieder zum Ausdruck bringen sollten. Beispielhaft hierfür ist das „Motor-SA Schlesierlied“ aus der „Kampfzeit“ mit dem Titel „Was rattert und knattert“ - eine Umdichtung des Liedes „Lützows wilde, verwegene Jagd“.

„Was rattert und knattert und donnert daher, als käme der Teufel gefahren/ durchs Schlesierland wohl Kreuz und Quer?/ Ein braunes, ein wildes, verwegenes Heer!/ Und fragt ihr, was sind das für Scharen?/ Dann klingt es im Jubel tari, tara, das ist, das ist Hitlers schlesische Motor-SA, das ist Hitlers schlesische Motor-SA/ Auf guten und schlechten Wegen fährt keiner so verwegen, wie Hitlers Motor-SA, wie Hitlers Motor-SA." ${ }^{11}$

Die Motorkämpfer bezeichneten die „allgemeine“ SA, die sich zumeist marschierend fortbewegte, in etwas despektierlichem Ton als „Fuß-SA“. Diese abschätzige Haltung gibt auch der Text des Niederschlesischen Motor-SA-Liedes wieder:

„Wem Gott will rechte Gunst erweisen/ den schickt er zur Motor-SA/ den läßt er nicht zu Fuße reisen/ mit Vollgas sind wir schneller da!/ Die Fuß-SA muß gräßlich schwitzen/ sie

79 Vgl. ebenda.

80 Zit. nach: Ostland Treuefahrt (Broschüre), o. O., o. J. (wahrscheinlich 1933), S. 48.

81 „Was rattert und knattert“, 1. Strophe, abgedruckt in: SA (Hrsg.): SA-Liederbuch, S. $107 \mathrm{ff}$. 
gönnt das Fahren uns nicht sehr/ und wenn vorbei wir an ihr flitzen/ ruft sie was „Liebes“ hinterher!" 82

Die NSDAP hatte bereits seit ihrer Wiedergründung 1925 am Aufbau einer umfangreichen Parteiorganisation mit Ämtern für Außenpolitik, Presse, Wirtschaft, Innenpolitik und Rechtsfragen gearbeitet. Die nationalsozialistische Bewegung sollte nach den Vorstellungen Hitlers, die er in seinem Buch "Mein Kampf" niedergelegt hat, so aufgebaut sein, dass sie "nicht nur in sich selbst den kommenden Staat trägt, sondern ihm auch bereits den vollendeten Körper ihres eigenen Staates zur Verfügung stellen kann" ${ }^{83}$ Der Oberste SA-Führer Röhm ergriff nach Wiederantritt als SA-Chef 1931 Strukturmaßnahmen, um diese Forderung auch in der SA in die Praxis umsetzen zu können. Unter dem Dach der SA entwickelte er ein nach beruflichen Sparten, sportlichen und technischen Neigungen ausdifferenziertes System mit zahlreichen Unter- und Nebenorganisationen. ${ }^{84}$ Das weit verzweigte System der nationalsozialistischen Organisationen war ein miniatürliches Abbild des kommenden Staates und erleichterte nach der politischen Machtübernahme im Januar 1933 die gesellschaftlichen Gleichschaltungsbestrebungen. Durch die Gründung von Motor-, Marine-, Flieger- und Reiterformationen unter dem Dach der SA gelang es, eine vorteilhafte Wechselwirkung zu erzielen: Man trug das nationalsozialistische Gedankengut in viele Bereiche des Berufslebens und der Gesellschaft und stärkte im Gegenzug durch die Werbung von Automobilisten, Fliegern und anderen Aktiven die Handlungsmöglichkeiten der Bewegung. Da es keine eigene NS-Sportorganisation gab, deckten die SA und ihre Untergliederungen zusätzlich die sportlichen Bedürfnisse der Mitglieder ab. Die mannigfaltigen politischen und propagandistischen Anforderungen ließen es im Falle des NSKK und der Motor-SA jedoch nicht zu, Motorrad fahren als sportliche Übung zu verstehen. Zudem hätte man bei einer stärkeren Betonung des sportlichen Elements in Form von Wettbewerben und Fahrten mit dem Angebot der Automobil- und Motorradvereine konkurrieren müssen. 85

Die Aufteilung zwischen den aktiven Kräften, die in einem Spezialsturm dienten, und den Mitgliedern und Förderern der NS-Bewegung, die sich in einer vereinsartig aufgebauten Gruppe mit dem Namen „Korps“ zusammenfanden, existierte nicht nur im Bereich des Kraftfahrwesens, sondern auch bei den nationalsozialistischen Flieger- und Marineformationen. Die SA-Marinestürme, darunter

82 Abgedruckt in: Ostland Treuefahrt (Broschüre), S. $68 \mathrm{f}$.

83 Vgl. Hitler: Mein Kampf, 2. Bd., S. 503.

84 Unter- und Nebenorganisationen der SA 1932 zur Förderung der nationalsozialistischen Bewegung im Allgemeinen und zur Unterstützung der SA im Besonderen: Motorstürme, Marinestürme, Fliegerstürme, Reiterstürme, Pionierstürme, Reichsführerschulen, Sanitätsdienst, Kapellen, Propagandastürme; vgl. Bessel: Political Violence, S. 31.

85 Teichler, der die Sportprogrammatik und Sportpraxis der oppositionellen NSDAP 19191932 untersuchte, stellte bei der NSDAP das Fehlen einer eigenständigen Sportorganisation fest. Trotz einer gewissen Sportkonjunktur in den Jahren 1926 bis 1930 kehrte die SA in der Endphase der Weimarer Republik wieder zu einer reinen Sturmabteilung zurück. Grund dafür könnte der schnell vollzogene Wandel zu einer Massenpartei ab 1930 gewesen sein, die den Aufbau eines NS-Sportverbandes nicht mehr zuließ; vgl. Teichler: Internationale Sportpolitik, S. 29, 35. 
der Marinesturm Hamburg, der im November 1931 etwa 120 Seeleute, vorwiegend Schiffsoffiziere, umfasste, zielte nach Angaben des Landeskriminalpolizeiamtes I Berlin auf eine aktive Beteiligung am politischen Kampf. ${ }^{86}$ Fast alle Mitglieder des Marinesturms waren auch Mitglieder des „Nationalsozialistischen Marinekorps". Die Mitgliedschaft im Marinekorps konnten ausschließlich Parteimitglieder erwerben, die bei der ehemaligen kaiserlichen Marine oder bei der Reichsmarine gedient hatten. ${ }^{87}$ Der Zweck der Vereinigung bestand darin, durch den Aufbau von Motorbootflotillen die „Propagandatätigkeit auf dem Wasser" voranzutreiben. Das NS-Marinekorps sah sich in der "Tradition der ruhmreichen alten Kriegsmarine“ und trat für die „Pflege und Erhaltung des Wehrgedankens zur See im deutschen Volke" ein. ${ }^{88}$ Eine ähnliche Entwicklung lässt sich bei den nationalsozialistischen Fliegern beobachten. Einzelne SA-Fliegerstaffeln, die sich zumeist von privaten Clubs abgespalten hatten, bestanden bereits seit 1931.89 Im Januar 1932, also rund ein Jahr später als im Bereich des Kraftfahrwesens, förderte die OSAF die organisatorische Fortentwicklung der Fliegerstürme und gründete das "Nationalsozialistische Fliegerkorps" (NSFK). ${ }^{90}$ Die Eintragung des NSFK als eingetragener Verein des bürgerlichen Rechts mit Hermann Göring als Präsident an der Spitze geschah im Hinblick auf die besondere Beobachtung des Auslands, der die zivile Luftfahrt im Rahmen der Beschränkungen des Versailler Vertrages ausgesetzt war. ${ }^{91}$ Die Angehörigen der SA- und SS-Fliegerstürme wurden aufgefordert, ihren Beitritt zum NSFK zu erklären. ${ }^{92} \mathrm{Da}$ die Mitglieder über ein eigenes Flugzeug, zumindest aber über einen Flugschein verfügen mussten, war der potenzielle Mitgliederkreis entsprechend klein. Die Deutsche Verkehrsflug AG in Franken, deren Mitarbeiter Mitglieder des NSFK waren, stellte für Veranstaltungen der NSDAP ihre Flugzeuge zur Verfügung. Für wichtige Einsätze standen für das Fliegerkorps, und somit für die NSDAP, 21 Verkehrsflugzeuge und sechs Sportflugzeuge bereit.93

Neben der Trennung in aktive Sturmangehörige der Motor-, Marine- und Flieger-SA und den als eine Art Reserve einsatzbereiten Korpsmitgliedern von

$86 \mathrm{Vgl}$. Auszug aus den Mitteilungen des Landeskriminalpolizeiamtes I Berlin vom 1. 11. 1931, BArch NS 23/470. Der Motorsturm Hamburg unterhielt eine Yacht. Die Bootsbesitzer stellten ihre Boote dem Sturm zur Verfügung.

87 Vgl. Richtlinien des Nationalsozialistischen Marine-Korps, StA München, Pol. Dir. 6822. Besitzern und Führern von Segel- und Motorbooten stand es offen, Fördermitglieder zu werden.

$88 \mathrm{Vgl}$. ebenda.

89 Vgl. Krause: Hamburg wird braun, S. 145.

90 Vgl. Der Bayerische Staatsminister des Innern über die SA 1931, in: Bericht des bayerischen Staatsministers des Innern: "Die Nationalsozialistische Arbeiterpartei", S. 13 f., BArch NS 26/317.

91 Das NSFK wurde am 1. 1. 1932 aufgestellt und als Verein eingetragen. An der Spitze stand als Präsident Hauptmann Göring. Das NSFK war der OSAF unterstellt; vgl. Verordnungsblatt der OSAF vom 30.11. 1931, betr. Nationalsozialistisches Fliegerkorps (NSFK). Vgl. dazu auch Cordts: Junge Adler, S. $41 \mathrm{f}$.

92 Das Fliegerkorps war korporativ der Nationalen Deutschen Luftfahrtvereinigung angeschlossen; vgl. Verfügung des RFSS vom 14. 1. 1932, StA München, Pol. Dir. 6822.

93 Vgl. Hambrecht: Der Aufstieg der NSDAP in Mittel- und Oberfranken, S. $314 \mathrm{f}$. 
NSKK, NSFK und NS-Marinekorps gab es einen weiteren generellen Unterschied zwischen den Spezialstürmen und den entsprechenden Korps. Die Stürme konzentrierten sich ausschließlich auf Aufgaben in der SA, wohingegen in den Korps bereits vor 1933 gesellschaftspolitische, wirtschaftliche und militärische Forderungen formuliert wurden, die über die Notwendigkeiten eines funktionierenden Propagandaapparates hinausgingen. Das Plädoyer des Marinekorps für den "Ausbau der deutschen Seemacht" ${ }^{\text {" }}$, die Forderung des NSKK nach einer „Nationalisierung des deutschen Motorwesens" 95 und des NS-Fliegerkorps nach einer „starken deutschen Luftfahrt“ 96 sind Ausdruck der Vision eines militärisch wieder erstarkten und wirtschaftlich potenten Deutschlands - Forderungen, die auch der bürgerliche Revisionismus im Sinne eines „Endes der Tributzahlungen“ und einer „Erlangung der militärischen Gleichberechtigung“ vor 1933 durchaus teilte. ${ }^{97}$

\section{Der Motor als politisches Instrument: Die „Eroberung der Straße“}

\section{Propaganda im Wabljabr 1932}

„Es gilt nunmehr, anknüpfend an unsere stolze Geschichte, die nationalsozialistische Motorisierung zum Endkampf zu rüsten. Als der beweglichste Teil der braunen Front gehören wir in die vorderste Linie!"98 Mit diesen Worten rief der stellvertretende Korpsführer Hühnlein am 17. Juni 1932 die nationalsozialistischen Kraftfahrer zu besonderem Engagement für die Bewegung auf.

Die Propaganda der NSDAP wurde und wird von Historikern und Publizisten als Meilenstein im Aufstieg der nationalsozialistischen Bewegung gewertet. ${ }^{99}$ Man ist auch heute noch geneigt, den Werbemethoden deshalb ein so starkes Gewicht einzuräumen, weil alles, was die NS-Bewegung und ihre Wehrverbände von anderen Parteien scheinbar unterschied, als mögliches Erfolgsmittel interpretiert werden kann, zumal auch die nationalsozialistischen Funktionsträger, allen voran Joseph Goebbels, die Machtübernahme als Ergebnis der modernen Massenpsychologie und des technischen Propagandaaufwandes darstellten. Historiker wie Gerhard Paul hingegen verweisen in ihren Darstellungen die Allmacht der Propaganda in den Bereich der Legendenbildung, da einer offensiven Nutzung neuer Medien und technischer Hilfsmittel durch die Selbstfinanzierung der NSDAP

94 Richtlinien des Nationalsozialistischen Marine Korps, StA München, Pol. Dir. 6822.

95 Der SA-Mann vom 5. 1. 1932: „Nationalsozialistische Kraftfahrer!“

96 Cordts: Junge Adler, S. 42.

97 Salewski: Zur deutschen Sicherheitspolitik in der Spätzeit der Weimarer Republik, S. 125.

98 Zit. nach Oppermann: Unter den Sturmstandern, S. 71.

99 Vgl. Zeman: Nazi Propaganda; Bracher: Die deutsche Diktatur, S. $160 \mathrm{ff}$. Auch Ludolf Herbst zieht eine direkte Verbindungslinie zwischen Propaganda und politischem Erfolg. Die NSDAP habe wie keine andere Partei der Weimarer Republik die Propaganda als Waffe des politischen Kampfes eingesetzt: „Dieser Modernität verdankte sie nicht zuletzt ihren Erfolg“; ders.: Das nationalsozialistische Deutschland 1933-1945, S. 85. 
enge Grenzen gesetzt waren. ${ }^{100}$ Regionale Studien, die über den Aufstieg der NSDAP im Reich in den letzten Jahren erstellt wurden, geben über den unterschiedlichen Wirkungsgrad der Propaganda Aufschluss. Das Beispiel Saarland zeigt, dass auch eine systematische Partei- und Wahlkampfpropaganda bis 1933 nur eine geringe Wirkung entwickeln konnte. ${ }^{101}$ Uwe Rennspieß weist am Beispiel Ahlen nach, dass der NSDAP ohne propagandistischen Einsatz und trotz mangelnder Organisation politische Wahlerfolge zuteil wurden, die auf das überregional vermittelte Image der Partei zurückzuführen sind. ${ }^{102}$ Mathias Rösch arbeitet für den Raum München heraus, dass die NSDAP im Bereich der Großveranstaltungen den politischen Gegnern überlegen war. Er betont aber zugleich die Schwierigkeit, die Propagandaaktionen und den Erfolg der Partei in einen ursächlichen Zusammenhang zu stellen. ${ }^{103}$ Wie die lokalen Untersuchungen über die höchst unterschiedliche politische Entwicklung der NSDAP vor 1933 zeigen, folgte der Aufstieg keinem einheitlichen Schema. Vielmehr war er in hohem Maße abhängig von religiösen und politischen Traditionen, soziokulturellen Milieus, Norm setzenden Persönlichkeiten und dem Presseklima in der Region. ${ }^{104}$ Die Propaganda kann also nicht isoliert vom politischen und sozialen Kontext betrachtet werden.

Dieser Vorbehalt gilt auch für die Einschätzung der Rolle des Kraftfahrkorps und der Motor-SA innerhalb des Propagandaapparates der Bewegung. Die Propagandabemühungen dürfen nicht in eine direkte Beziehung zur Akzeptanz der NSBewegung und ihrer Wahlerfolge gesetzt werden, auch wenn die Führer der NSDAP und die Chronisten des NSKK nach 1933 dies den Zeitgenossen und der Nachwelt glaubhaft machen wollten.

Hitler beschrieb in seinem Buch „Mein Kampf" seine Antipathien gegen die sozialdemokratischen Straßendemonstrationen im Vorkriegs-Wien und kritisierte den seiner Meinung nach unrechtmäßigen Anspruch der Sozialisten auf öffentliche Präsenz. ${ }^{105}$ Das Ziel nationalsozialistischer Demonstrationspolitik bestand darin, kommunistischen und sozialdemokratischen Kreisen die Besetzung des öffentlichen Raumes streitig zu machen. Goebbels stellte die „Eroberung der Straße" 1934 rückwirkend als erfolgreiches Mittel zur Gewinnung der staatlichen Gewalt dar:

„Man hielt es in bürgerlichen Kreisen für unfein und wenig vornehm, auf die Straße zu gehen und für politische Ideale zu demonstrieren und einzutreten. Die Straße ist nun einmal das Charakteristikum der modernen Politik. Wer die Straße erobern kann, der kann auch die Massen erobern; und wer die Massen erobert, der erobert damit den Staat." 106

Goebbels bezog sich bei seinen Ausführungen auf den „Kampf um Berlin“. Aufgrund der zahlenmäßigen Unterlegenheit erreichten die Nationalsozialisten dort

100 Vgl. Paul: Aufstand der Bilder, S. 256.

101 Vgl. ders.: Die NSDAP des Saargebietes 1920-1935, S. $139 \mathrm{f}$.

102 Vgl. Rennspieß: Aufstieg des Nationalsozialismus, S. 228.

103 Vgl. Rösch: Die Münchner NSDAP, S. 540-544.

104 Vgl. Rennspieß: Aufstieg des Nationalsozialismus, S. 307.

105 Vgl. Hitler: Mein Kampf, S. $42 \mathrm{ff}$.

106 Goebbels: Kampf um Berlin, Bd. 1, S. 86. 
ihr Ziel erst nach der Machtübernahme, und zwar mit Hilfe staatlich bevollmächtigter Politiker und der eingeleiteten Terrormaßnahmen gegen Kommunisten, die zusammen mit SPD-nahen Gruppen das Demonstrationsgeschehen in Berlin bislang dominiert hatten. ${ }^{107}$ Die öffentliche Präsenz der SA war vor 1933 auch aus anderen Gründen von großer Bedeutung: Aufmärsche und Demonstrationen förderten die Identifikation des einzelnen SA-Mannes mit der Bewegung und trugen zur Motivation der Anhänger bei. ${ }^{108}$ Sie waren Mittel der politischen Sozialisation und stärkten das Zusammengehörigkeitsgefühl der Mitglieder. Weil es der NSDAP im Parlament bis 1933 nicht gelang, die Macht im Staat zu übernehmen, war sie auf die außerparlamentarische Propaganda der SA angewiesen. ${ }^{109}$

Zur Verstärkung dieser Propaganda war auch die Motor-SA aufgerufen. Das Wahljahr 1932 stellte die Einsatzbereitschaft und die Organisation des NSKK und der Motor-SA vor steigende Anforderungen. Die Verfügung der OSAF vom 4. Februar 1932 über den Einsatz der Motorverbände in den Wahlkämpfen suchte diesen gerecht zu werden. ${ }^{110} \mathrm{Zu}$ den Vorbereitungen, denen sich die Motordienststellen der Motor-SA und des NSKK intensiv widmen sollten, zählten die technische Instandhaltung der Fahrzeuge, die Spendensammlung für den Betriebsstoff, die Neuzulassung von abgemeldeten Fahrzeugen, Preisabsprachen mit befreundeten Tankstellenbesitzern ${ }^{111}$ und die Regelung von Betriebsstoffzuweisungen an die einzelnen Stürme. Soweit möglich unterstützte die Inspektion die Stürme mit Benzinkontingenten. Die organisatorische Hauptarbeit lag bei den Oberstaffelführern der Motor-SA, die idealerweise auch die Bereichführer des NSKK waren und den Einsatz der Motorformationen in ihrem Gebiet in Zusammenarbeit mit den SA-Untergruppenführern und zuständigen politischen Gauleitern koordinierten. Die Motor-SA unterstützte die SA 1932 im Versammlungsschutz und bei Propagandaaktionen. Die Motor-SS wurde entsprechend den Weisungen der zuständigen SS-Führer eingesetzt. Das NSKK war für die Bereitstellung der benötigten Fahrzeuge für den Transport von Rednern oder von nationalsozialistisch gesinnten Wählern zu den Wahllokalen verantwortlich. ${ }^{112}$ Hühnlein forderte das Engagement des NSKK speziell auf diesem Gebiet: „Vergeßt nicht Eure besondere Aufgabe, das flache Land zu bearbeiten. Es darf kein Dorf, keinen Weiler geben, wohin nicht Eure Unterstützung reicht. Holt den Letzten zur Wahlurne heraus." 113

107 Vgl. Ehls: Protest und Propaganda, S. 396.

108 Vgl. Paul: Die NSDAP des Saargebietes 1920-1935, S. 144.

109 Vgl. Ehls: Protest und Propaganda, S. 365.

110 Es war „Ehrensache“, kostenlos zu fahren. Da dies aber nicht allen Mitgliedern möglich war, galt der Grundsatz: Die Kosten der Fahrt tragen die politischen Dienststellen, die die Fahrzeuge anfordern; vgl. OSAF-Verfügung vom 4. 2. 1932, betr. Einsatz der Motorverbände im Wahlkampf, BayHStA München, MInn 81625.

111 Das Korps hatte einen Preisnachlass mit der „Aral-Gesellschaft“ ausgehandelt. Falls der Tankstellenkunde eine Dienstfahrt für das Korps nachweisen konnte, erhielt er Rabatt; vgl. Pflichtappell des NSKK der NSDAP-Gruppe Hochland am 19. 7. 1932, StA München, Pol. Dir. München 6835.

112 Vgl. OSAF-Verfügung vom 4. 2. 1932, betr. Einsatz der Motorverbände im Wahlkampf, BayHStA München, MInn 81625.

113 Monatsblätter des NSKK vom März 1932, „Kameraden“. Im Vorfeld von Wahlen wur- 


\section{Die Motor-SA im Straßenkampf}

Das größte Plus, das die Motor-SA gegenüber der „Fuß-SA“ verbuchen konnte, war ihre rasche Beweglichkeit. Wenn die SA im Straßenkampf den ReichsbannerAngehörigen oder Rotfront-Kämpfern zahlenmäßig unterlegen war und Hilfe benötigte, forderte sie, soweit möglich, telefonisch Verstärkung an. Die alarmierten SA-Motortrupps waren schneller als andere SA-Einheiten am Brennpunkt. Außerdem konnte das NSKK zur Unterstützung hinzugezogen werden, um komplette SA-Mannschaften zu transportieren. Einen taktischen Vorteil im Straßenkampf erreichte man durch die Verwendung von Scheinwerfern, die es möglich machten, Hinterhalte auszuleuchten. ${ }^{114} \mathrm{Zu}$ den nützlichen Ausstattungsgegenständen der Motor-SA rechnete der NSKK-Chronist Theodor Oppermann darüber hinaus die Sturzhelme der Fahrer, die sich bei Gewalttätigkeiten nach seinen Worten als besonders "hieb- und stichfest" erwiesen.115

Glaubt man den nationalsozialistischen Beschreibungen aus der Kampfzeit, dann war die „Schlägerelite“ auf Seiten der Nationalsozialisten und Kommunisten bei den Marineeinheiten der großen Hafenstädte zu finden. ${ }^{116}$ Jedoch legten auch Mitglieder von SA-Motorstürmen mancherorts eine große Gewaltbereitschaft an den Tag. Nach den Ausführungen des Gründers des SA-Motorsturmes in München sollte die motorisierte Einheit das „Überfallkommando der SA sein, das bei Schlägereien mit politischen Gegnern sofort auszurücken" habe. ${ }^{117}$ Der Motorsturm übernahm auch regelmäßig Bereitschaftsdienste am Braunen Haus, der Parteizentrale der NSDAP, in München. ${ }^{118}$ Auch der hessische SA-Motorsturm in Langen, der einen festen Stützpunkt mit Funkstation in einem Café unterhielt, zeigte sich extrem gewaltbereit. Er wurde immer dann eingesetzt, wenn eine Einheit in der Region benötigt wurde, die kurzfristig und schnell handlungsfähig sein konnte. Wegen seines brutalen Auftretens war der Motor-SA-Sturm in der ganzen Region als „Rollkommando" und „Mord-Sturm" berüchtigt.119

Seit Ende der zwanziger Jahre veranstaltete die SA nicht nur zu Wahlzeiten, sondern regelmäßig Aufmärsche und so genannte "Propagandafahrten“ in das agrarische Umland der Städte. Vorbilder dieser Unternehmungen waren die Landagitation der KPD und die Propagandafahrten des Reichsbanners, der bereits 1925 seine Werbung mit Kraftwagen verstärkt hatte. ${ }^{120}$ Die Nutzung des motorisierten Transports brachte der SA, besonders in ländlichen Gegenden mit größeren Entfernungen zwischen den Städten und Dörfern, taktische Vorteile. Plötz-

den die Fahrzeugbesitzer gesondert aufgefordert, ihre Fahrzeuge der Leitung des NSKK zu überlassen; vgl. Pflichtappell des NSKK der NSDAP Gruppe Hochland am 19.7. 1932, StAMünchen, Pol. Dir. München 6835.

114 Vgl. Oppermann: Unter den Sturmstandern, S. 38.

115 Vgl. ebenda.

116 Vgl. Okrass: „Hamburg bleibt rot“, S. 202 ff.

117 Lageberichte der Polizeidirektion München vom 24. 10. 1930, S. 9, StA Amberg, Regierung der Oberpfalz, KdI, Abgabe 1949 ff. Nr. 13907.

118 Rösch: Die Münchner NSDAP, S. 252.

119 Vgl. Fogel: Nationalsozialismus in der Dreieich, S. 122; Pingel: Die Machtergreifung der NSDAP in Darmstadt, S. $353 \mathrm{f}$.

$120 \mathrm{Vgl}$. dazu ausführlicher S. $55 \mathrm{ff}$. dieser Arbeit. 
liche Invasionen von 200 bis 300 SA-Männern „sprengten“ sozialdemokratische Versammlungen und konnten daran von den isolierten Reichsbanner-Gruppen im Ort nicht gehindert werden. $\mathrm{Da}$ die SA-Männer auch gegenüber den anwesenden Polizeikräften in der Überzahl waren, setzten sie sich einfach über das Verbot des Uniformtragens hinweg und veranstalteten Aufmärsche unter freiem Himmel. ${ }^{121}$

Diese überfallartigen „Eroberungen“ entwickelten sich zu einem Charakteristikum der Propagandataktik der SA in den ländlichen Gebieten. Am 6. März 1927 besetzten von außerhalb anrückende SA-Kommandos den Ort Nastätten (Hessen-Nassau) und lieferten sich mit dem politischen Gegner und der Polizei gewalttätige Auseinandersetzungen. ${ }^{122}$ Auch größere Städte wurden von derartigen Aktionen heimgesucht. Am Abend des 22. Juni 1932 beförderte die SA rund 2000 SA-Männer aus Anlass einer Parteiversammlung nach Breslau. Sie nutzte die Gelegenheit zu gewalttätigen Ausschreitungen in den Arbeiterbezirken der Stadt. Richard Bessel kommt für die östlichen Provinzen Preußens zu dem Urteil:

„The mobility of the SA greatly increased its effectiveness, and it is revealing that neither the Communists nor the Social Democrats seem to have had the access to motor vehicles which the Nazis obviously enjoyed." 123

Es mangelte auf Seiten der Sozialdemokraten an einem gut ausgebauten Fahrdienst für die Beförderung der sozialdemokratischen Redner und Parteisekretäre. ${ }^{124}$ Auch machten SPD-Gruppen, die sich auch mit Fahrrädern auf Werbefahrten aufs flache Land begaben, die unangenehme Erfahrung, ungeschützt nationalsozialistischen Überfällen ausgesetzt zu sein und auf keine mobile Verstärkung aus nahe gelegenen Orten hoffen zu können. In den NS-Hochburgen Lüneburger Heide, Pommern und Mark Brandenburg setzte die SPD aus diesem Grunde 1932 verstärkt Lastwagen und Motorstaffeln ein. ${ }^{125}$ Kommunisten stellten den mobilen SA-Rollkommandos eigene Einheiten entgegen, die die Lastwagen mit SA-Einheiten beim Verlassen der Orte attackierten. ${ }^{126}$

Erlebnisberichte von SA-Motorstürmen geben Aufschluss über den Verlauf der so genannten Werbefahrten aus dem Jahre 1932, die aus Gründen der Sympathiegewinnung einen friedlichen Verlauf nehmen sollten. Der Motorsturm beim Gausturm Berlin-Brandenburg ging am Wochenende, als Begleitkorso des Gauleiters, regelmäßig auf Propagandafahrt durch märkische Dörfer. Eine Viertelstunde voraus fuhr ein Lkw, der die Umgebung mit lauter Musik beschallte, in das Dorf. Dann folgte der Motorsturm. Nachdem der Sturm im offenen Viereck vor dem Kriegerdenkmal Aufstellung genommen hatte, hielt der Sturmführer eine Anspra-

121 Vgl. Bessel: Political Violence, S. 82.

122 Dirk: Antisemitische Kriminalität, S. $207 \mathrm{f}$.

123 Ebenda, S. 83. Weitere Beispiele motorisierter „Invasionen“ nennt Blackbourn: „Die meisten von ihnen haben Räder", S. 147.

124 Pyta beschreibt anschaulich den Mangel an Fahrzeugen bei den Parteisekretären und die Probleme, die sich bei der Nutzung von Fahrrädern ergaben; vgl. Pyta: Gegen Hitler, S. $410 \mathrm{f}$.

125 Vgl. ebenda, S. 418.

126 Vgl. Bessel: Political Violence, S. 176, Anmerkung 51. 
che vor den Ortsbewohnern. Danach erfolgte die Weiterfahrt zum nächsten Dorf. Wenn die Motor-SA ihren Besuch vorher angekündigt hatte, hängten manche Hausbewohner Hakenkreuzfahnen aus dem Fenster, manche erhoben den Arm zum Hitlergruß. Da es sich meistens um Wochenendfahrten handelte, stellten sympathisierende Bauern der Motor-SA Übernachtungsplätze zur Verfügung. ${ }^{127}$ Eine Strophe des Liedes „Lasst die Maschinen brausen“ aus dem Liedgut der Berliner Motor-SA veranschaulicht das selbst entworfene Image vom entschlossenen Motorkämpfer in politischer Mission:

„Nichts hält uns ab, kein Stürmen und kein Regen/ auf den Maschinen tun wir unsre Pflicht/ Dem Feinde fahren mutig wir entgegen/ denn unsre Fahrt führt uns durch Nacht zum Licht/ Es rattern unsre Räder, denn wissen soll's ein jeder/ Die unterm Hakenkreuz vorüberzieh'n, die sind vom Motorsturm Berlin." 128

\section{Die symbolische Macht des Motors}

Die Propagandafahrten, vorzugsweise in ländliche Gebiete, folgten nicht nur politischen Intentionen. Das gemeinsame Naturerlebnis, der Kameradschaftsgeist und die Ausflugsstimmung waren Erlebnismomente, die in keiner Chronik fehlen durften. ${ }^{129}$ Wie Gerhard Paul in seiner Studie „Aufstand der Bilder“ über die NSPropaganda vor 1933 herausgearbeitet hat, war die propagandistische Hauptaufgabe des öffentlichen Auftretens der SA „die ästhetische und akustische Okkupation des öffentlichen Raumes durch die Vermittlung sinnenmobilisierender innerer Bilder" ${ }^{130}$ Im Einsatz der Motorformationen kamen diese emotionalen Elemente der NS-Propaganda besonders zum Tragen. Von weitem bereits kündigten die donnernden Motoren den Stadt- und Dorfbewohnern das Nahen der Motor$\mathrm{SA}$ an. Das Röhren der Motoren verstärkte klangtechnisch den Eindruck einer Eroberung. Was die „Fuß-SA“ mit ihrem militärischen Marschtritt, der Marschmusik, den Liedern und Rufen erreichte, bewirkten Motorstürme durch die lauten und kernigen Motorengeräusche auf noch massivere Weise: die „akustische Okkupation des öffentlichen Raumes".

Motorisierte Aufzüge sprachen überdies die visuellen Sinne der Zuschauer an. Die SA war sich der propagandistischen Wirkung einer gut aufgestellten Kraftfahrzeugkolonne bewusst. ${ }^{131}$ Lange Kolonnen mit wehenden Bannern hinterließen besonders in ländlichen Gebieten, in denen Kraftwagen seltene Anschauungs-

127 Vgl. die Berichte der Motor-SA von den Wahlkämpfen 1932, BArch NS 24/84.

128 „Lasst die Maschinen brausen“, 3. Strophe, abgedruckt in: SA (Hrsg.): SA-Liederbuch, S. $74 \mathrm{ff}$.

129 Diese Elemente betont auch Hellmut Oldenbourg, Truppführer des Münchner Motorsturms I in seinem Bericht im Völkischen Beobachter vom 2. 7. 1931 (Wochenbeilage): "Auf Dienstfahrt für Adolf Hitler".

130 Paul: Aufstand der Bilder, S. 135; vgl. auch die Beispiele bei Blackbourn: „Die meisten von ihnen haben Räder", S. 144.

131 In einer Dienstvorschrift aus dem Jahre 1932 heißt es: „Jede Kraftwagenfahrt hat propagandistische Bedeutung und nützt oder schadet unserer Bewegung je nach dem Eindruck, den sie auf die Öffentlichkeit macht", SA (Hrsg.): Dienstvorschrift für die SA der NSDAP, H. 3, Dießen 1932, S. 278. 
objekte waren, einen bleibenden Eindruck. ${ }^{132}$ Durch das Kolonnenfahren und die Fahrzeugbeherrschung vermittelte die Motor-SA ein Bild von Geradlinigkeit und Disziplin. Dieser Eindruck kam dem Bedürfnis der Bürger nach Sicherheit und Ordnung entgegen und sollte vergessen machen, dass es gerade die nationalsozialistischen Wehrverbände waren, die die öffentliche Sicherheit permanent verletzten. Geht man von einer idealtypisch gestalteten Motorkolonne aus, die freilich in der Realität aufgrund der mangelnden Ausstattung an Fahrzeugen und Uniformen vor 1933 so nicht aufgestellt werden konnte ${ }^{133}$, dann symbolisierte sie totalitäre Ordnungsvorstellungen von einer formierten, nach dem Führerprinzip geordneten patriarchalen Gesellschaft. Hinzu kommt, dass Motorstürme durch ihr lautes und mächtiges, alle Widerstände „überrollendes“ Auftreten die nationalsozialistische Entschlossenheit und Siegeszuversicht ins Bild zu setzen vermochten. Doch waren an diese Demonstrationen der Stärke nicht nur positive Konnotationen geknüpft. Es ist anzunehmen, dass sich viele Bürger durch den Lärm und die Luftverschmutzung belästigt fühlten und Straßendemonstrationen dieser Art als einschüchternde Provokation und illegitime Besetzung des öffentlichen Raumes ablehnten. ${ }^{134}$ Es muss also von einer ambivalenten Wirkung von SA-Aufmärschen und Rollkommandos auf den Betrachter ausgegangen werden, doch verfehlte die SA gerade in ländlichen Gebieten nicht das angestrebte Ziel, die Aufmerksamkeit der Einwohnerschaft auf sich zu ziehen. In den Städten allerdings kam es bisweilen vor, dass die Bevölkerung, wie im Vorfeld der Münchner Kommunalwahl am 8. Dezember 1929, als SS- und SA-Männer auf 48 Lastwagen im Dauerregen eine Propagandafahrt durch München unternahmen, kaum Notiz von derartigen Aktionen nahm. ${ }^{135}$

132 Mitteilungsblatt für das Nationalsozialistische Kraftfahr-Korps und die Motorstürme der SA und SS vom 1. 8. 1931: „Das Kraftfahrkorps im Dienste des Chemnitzer Gauparteitags", BArch NSD 42/3.

133 Durch das häufige Uniformverbot und die Minderausstattung der Fahrer mit Motorradhelmen konnten die Motor-SA-Männer nicht die gleiche Wirkung erzielen wie das NSKK nach der Machtübernahme, das sich mit einheitlichem Auftreten in Uniform, schwarzen Sturzhelmen und präzisem Kolonnenfahren in das Gedächtnis der Betrachter einprägte. Die idealtypische Stilisierung der Kolonnen durch die NSKK-Chronisten war eine Rückprojektion der Propaganda des „Dritten Reiches“ auf die Propaganda der Kampfzeit. Zur Ästhetik marschierender SA-Kolonnen vgl. Ehls: Protest und Propaganda, S. 385. Thomas Balistier untersuchte in seiner Studie: Gewalt und Ordnung, die Strukturen der nationalsozialistischen Kampfdemonstrationen vor 1933. Er erkennt in der SA-Kolonne ein Symbol für die vorweggenommene Volksgemeinschaft. Dabei geht Balistier von einer idealtypischen Ordnungsstruktur der SA aus und stellt den Realitätsgehalt der propagandistischen Stilisierungen in der nationalsozialistischen Presse nicht in Frage. Zuweilen bietet er auch psychoanalytisch inspirierte Deutungen an, die bizarr anmuten: „Die SA-Männer verkörperten die nationalen Massensymbole der Deutschen. Sie erschienen als Heer, als marschierender Wald“; ebenda, S. 198.

134 Es gab in den zwanziger Jahren zahlreiche Klagen der Einwohnerschaft an die Kommunen und Bezirksregierungen über den Staub und den Lärm, den Kraftfahrzeuge besonders auf ungeteerten Fahrbahnen verursachten; vgl. Nordrhein-Westfälisches Staatsarchiv Detmold (Hrsg.): Verkehr und Transport in Ostwestfalen-Lippe, S. $62 \mathrm{f}$.

135 Rösch: Die Münchner NSDAP, S. 347. Als weiteres Beispiel für das Desinteresse der Passanten führt Rösch die Propagandafahrten der Münchner SA im Wahlkampf 1928 an; ebenda, S. 182. 
Die Symbolik des Motors passte in vielerlei Hinsicht zum Wesen und Selbstverständnis der nationalsozialistischen Bewegung in der Zeit vor 1933. Die explosive und dynamische Kraftentfaltung entsprach sowohl der außerparlamentarischen Strategie „Eroberung der Straße“ als auch der umfassenden Selbstdarstellung als vitale, vorwärts strebende Bewegung, die die „Festgefahrenheit“ der Parteien hinter sich lässt. ${ }^{136}$ Ernst Jünger, der 1932 in seinem Werk „Der Arbeiter" eine Situationsanalyse seiner Zeit vornahm, erkannte in der Steigerung der Geschwindigkeit ein Indiz für den Anbruch einer neuen Herrschaftsform. Auch wenn Jünger seine Beobachtungen nicht speziell auf die NS-Bewegung bezog, sondern den Gesamtzustand der Gesellschaft im Blick hatte, liest sich sein Text wie eine Beschreibung der nationalsozialistischen Mobilisierungsbemühungen:

„Entsprechend sind die großen Theorien dynamischer Art, und man besitzt Macht, insofern man über motorische Energie verfügt - letzten Endes ist bereits der Wille zur Macht eine hinreichende Legitimation. Ebenso sind die Symbole, auf die man in millionenfacher Wiederholung stößt, Ausdruck einer Bewegungssprache, so der Flügel, die Welle, die Schraube, das Rad.“ 137

Die Nutzung moderner Fortbewegungsmittel harmonierte in idealer Form mit dem jugendlichen Image der SA, deren überwiegender Mitgliederanteil unter 30 Jahren lag. ${ }^{138}$ Die Beherrschung eines Fahrzeugs stellte eine besondere Herausforderung für SA-Männer dar, die sich zu allen Bereichen des Wehrsports, in denen männliche Physis gefordert war, hingezogen fühlten. NS-Propagandisten idealisierten Motor-SA-Männer als „ganze Kerle“, „die nicht Tod noch Teufel fürchteten, wenn es galt, mit ihren schnellen Rädern in stetem vernichtendem Kampf und Terror das Letzte einzusetzen"139. Es wird deutlich, dass die Verwendung von Kraftfahrzeugen für die SA nicht nur instrumentellen Charakter im Sinne einer Eroberungsstrategie hatte, sondern auch ideal zum Inhalt des faschistischen Lebenskonzeptes passte, das Sven Reichardt in seiner Vergleichsstudie der faschistischen Wehrbünde SA und italienischer Squadrismus beschreibt. ${ }^{140}$ Die Motorisierung als Verkörperung des „Heroismus der Jugend“ verband sich dabei mit dem Jugendpathos und der aufgesetzten Virilität der Faschisten.

Der Einsatz des Motors lässt sich im übertragenen Sinne auch als Protestform gegen die Bestimmungen des Vertrages von Versailles interpretieren, der ein vollständiges Verbot der Militärluftfahrt verhängt und die Motorisierung der Reichswehr als potenzielles Mittel zur Aufrüstung Deutschlands beschränkt hatte. ${ }^{141} \mathrm{Im}$

136 Vgl. zur gesteigerten Dynamik der Propaganda auch Blackbourn: „Die meisten von ihnen haben Räder", S. $143 \mathrm{f}$.

137 Jünger: Der Arbeiter, S. 247.

138 Jamin: Zwischen den Klassen, S. 88.

139 Schröder: Mit der Partei vorwärts, S. 134.

140 Vgl. ders: Faschistische Kampfbünde, S. 696, 705.

141 Neben dem Verkehrsflug, der in die Planungen einer „Schwarzen Luftwaffe“ mit einbezogen wurde, setzte die Reichswehr zur Ausbildung von Fliegern vor allem auf den nicht verbotenen Segelflug. Die Befürchtungen der Alliierten, Deutschland könne unter dem Deckmantel des Sports eine neue Luftwaffe heranziehen, waren so stark, dass sich das Deutsche Reich im Pariser Luftfahrtabkommen von 1926 verpflichten musste, den Motorflugsport nicht aus öffentlichen Mitteln zu unterstützen; vgl. Cordts: Junge Adler, 
Hinblick auf den Symbolwert des Motors sind allerdings zwei Einschränkungen vonnöten. Erstens: Das Kraftfahrzeug wurde von den Nationalsozialisten nur in seiner Bedeutung als Kampfinstrument rezipiert. Als Mittel zur Mobilitätssteigerung der Wohlhabenden war es dem Image der selbst ernannten Arbeiterpartei jedoch nicht dienlich. Zweitens: Die Symbolik des Motors fand keinen Eingang in die allgemeine und offizielle Bildersprache der Nationalsozialisten vor 1933.142 Dies lässt den Schluss zu, dass sich die Motorisierung als Sinnbild der Bewegung erst in der "Staatspropaganda" durchsetzen konnte und nur rückwirkend auf die „Kampfzeit“" übertragen wurde. ${ }^{143}$

\section{Kraftfahrzeug und Flugzeug - Hitlers Hilfsmittel im Wahljahr 1932}

Wendet man den Blick weg vom abstrakten Bild hin zum konkreten Einsatz motorisierter Fortbewegungsmittel, fällt auf, wie stark die Chronisten der Bewegung die Mobilität als Erfolgsrezept für den Aufstieg würdigten. Rückschauend beschrieb Theodor Oppermann den Nutzen des Motors folgendermaßen:

„Der Motor ermöglichte die ungeheure Wirkung der Versammlungsredner, die heute hier und morgen dort, oft mehrmals am gleichen Tage, sprachen. Der Motor beflügelte den Einsatz des NSKK, der SA und SS, spannte das dichte Netz der Propagandafahrten und steigerte die Stärke der Großkundgebungen. Der politische Wert des einzelnen Nationalsozialisten der Kampfzeit war die Vervielfältigung seines fanatischen Willens mit der Leistung des Motors! Der Kampf um ein neues Deutschland ist auf den deutschen Straßen erster bis vierter Ordnung entschieden worden!" 144

Besonders Hitlers positive Einstellung zu den modernen Transportmitteln Flugzeug und Auto wurde immer wieder als mitentscheidend für die politischen Wahlerfolge herausgestellt. Hitler selbst sprach den technischen Hilfsmitteln Verdienste am politischen Aufstieg der Bewegung zu: „Ohne den Kraftwagen, ohne das Flugzeug und ohne den Lautsprecher hätten wir Deutschland nicht erobert." 145 Unter Zuhilfenahme der motorisierten Fortbewegungsmittel unternahm Hitler 1932 eine ausgedehnte und öffentlichkeitswirksame Wahlkampftournee durch Deutschland. Im „Superwahljahr“ 1932, in dem zwei Wahlgänge für die Reichspräsidentenwahl, zwei Reichstagswahlen und zahlreiche Landtagswahlen stattfanden, legte Hitler in vier so genannten "Deutschlandflügen“ nahezu 50000 Flugkilometer zurück und sprach auf rund 150 Großveranstaltungen. Ansässige Stürme übernahmen den Schutz und die Begleitung des „Führers“ auf seiner Fahrt

S. 28. Insofern war der Motorflug in der Weimarer Republik auch ein Symbol für Deutschlands Streben nach Wiedergewinnung militärischer Souveränität.

142 Paul, der in seiner Studie "Aufstand der Bilder" die Arbeit der Reichspropagandaleitung, die wichtigsten Wahlkämpfe vor 1933, das Repertoire der propagandistischen Medien und die visuelle und verbale Inszenierung der Propaganda untersucht, blendet den Motor als Propagandamittel im Zusammenhang mit der Bildersprache aus. Offenbar spielte er im Zusammenhang mit den Anweisungen der Reichspropagandaleitung und den Plakatmotiven keine wesentliche Rolle.

143 Vgl. zum Sinnbild des Motors im „Dritten Reich“ S. 168 dieser Arbeit.

144 Oppermann: Unter den Sturmstandern, S. 8.

145 Zit. nach ebenda, S. 142. 
vom Flugplatz zu den Versammlungsorten. ${ }^{146}$ „Es war politische Propaganda, die selbst amerikanische Methoden in den Schatten stellte", jubelte Hitlers Pressechef Otto Dietrich. ${ }^{147}$ Besonders im Vorfeld der Reichstagswahl am 31. Juli 1932 setzte die Reichspropagandaleitung auf die Nutzung moderner Verkehrs- und Kommunikationsmittel als Träger und Medien der Propaganda. Es wurden Lautsprecherwagen für die Übertragung der Reden eingesetzt. ${ }^{148}$ Tatsächlich gelang es Hitler, in kurzer Zeit rund zwei bis drei Millionen Zuhörer direkt anzusprechen, ungleich mehr als ein anderer Politiker jemals zuvor. ${ }^{149}$ Die NS-Propaganda förderte Hitlers Image als volksnaher Politiker, der durch seine ausgedehnten Wahlkampfreisen um die Probleme des "kleinen Mannes“ in Stadt und Land wusste. Diesen Bezug stellte auch folgende absurde Behauptung her: „Weil Hitler Tag und Nacht auf der Landstraße war, in allen Mundarten Auskünfte über die Wege und Abzweigungen erhielt, kannte er das Land, seine Nöte und Möglichkeiten, seine innerste Struktur und seinen Rhythmus besser als irgend jemand seiner Gegner. "150

Die Reaktionen der Innenminister und Polizeibehörden

Die Innenminister der Länder waren über die umfangreichen Motorisierungsanstrengungen im Zuge der organisatorischen Änderungen in der SA und SS seit 1931 informiert. Die Polizeibehörden erhielten Anweisung zu prüfen, in welcher Beziehung Organisationen wie das NSKK und die Motorstürme zur OSAF standen, und zu untersuchen, wie weit ihre paramilitärischen Eigenschaften das von den Wehrverbänden ausgehende Gewaltpotenzial erhöhten. Nach Einschätzung der Polizeidirektionen trugen die Neben- und Unterorganisationen der Wehrverbände, wie sie das NSKK und die Motor-SA verkörperten, zu einer deutlichen Militarisierung des politischen Klimas bei. Die Organisationen der SA waren nach Ansicht des Bayerischen Innenministeriums nicht nur militärisch strukturiert, sondern auch militärisch ausgebildet. So hätten Motorstürme und andere Einheiten in vorausschauender Weise bereits die Einnahme von Ortschaften eingeübt. ${ }^{151}$ Den Behörden war außerdem bekannt, dass zur Nachrichtenübermittlung ein verdeckter Relaisdienst geschaffen worden war. ${ }^{152}$ Die Kraftfahrrelaisübungen

146 Der Motorsturm Kronach beteiligte sich am Begleitzug Hitlers auf seinem Weg nach Bayreuth am 30. 7. 1932; vgl. die Beschreibung: Großer Tag beim Motorsturm 24/M 77 Kronach, BArch NS 24/25.

147 Dietrich: Mit Hitler in die Macht, S. 70. Die Propaganda-Tour Hitlers gilt bis heute als „faszinierende[n] technische[n] Präsentation des ,Hitler-Mythos““; Wendt: Deutschland 1933-1945, S. 31.

148 Vgl. ebenda, S. 66-70.

149 Vgl. Paul: Aufstand der Bilder, S. 207.

150 Vgl. Oppermann: Unter den Sturmstandern, S. 8.

151 Der Bayerische Staatsminister des Innern über die SA 1931, in: Bericht des bayerischen Staatsministers des Innern: „Die Nationalsozialistische Arbeiterpartei“, S. 18, BArch NS 26/317.

152 Vgl. Der Badische Innenminister an den RIM vom 14. 3. 1931, abgedruckt in: Maurer u. a. (Bearb.): Staat und NSDAP 1930-1932, Dok. 26; Aus den Mitteilungen des Landeskriminalpolizeiamts (I) Berlin vom 1. 4. 1932, Nr. 7, Anlage R1 (Abschrift) Oberster SA-Führer vom 15.1. 1932 an die Gruppen, betr. Reichs-Relais, StA Münster, Politische Polizei III. Reich Nr. 387. 
unter Leitung des Inspekteurs der Motorstürme und -staffeln der SA und SS verfolgten den Zweck, reibungslose Nachrichtenverbindungen zwischen den verschiedenen Kraftfahrstäben herzustellen. Hierzu wurde die Übergabe von Stafetten geübt. ${ }^{153}$ Bei den Behörden verstärkten diese konspirativen Tätigkeiten das Misstrauen gegenüber der Verfassungskonformität der SA. ${ }^{154}$ Obschon Hitler Legalitätserklärungen abgab und die SA sich in ihren Satzungen vom militärischen Charakter ihrer Organisation distanzierte, um nicht gegen das Gesetz vom 12. Februar $1926 \mathrm{zu}$ verstoßen, das keine Vereinigungen mit militärischem Ziel oder Charakter zuließ, standen nach dem Urteil des Bayerischen Innenministeriums diese formalen Bekenntnisse in krassem Widerspruch zu den paramilitärischen Maßnahmen der NSDAP. ${ }^{155} \mathrm{Zu}$ den Gegenmaßnahmen der Länder zählten Umzugs- und Uniformverbote sowie die Beobachtung von NS-Funktionären. Die Kriminalpolizei durchsuchte einige Male das Haus des Verlegers der NSKK-Monatsblätter, Theodor Oppermann, in dem heimliche Besprechungen Hühnleins mit Gruppenstaffelführern stattfanden. ${ }^{156}$ Mit Artikel $\$ 4$ der Verordnung des Reichspräsidenten zur Bekämpfung politischer Ausschreitungen vom 28. März 1931, wonach Lastwagenfahrten aller Vereinigungen der behördlichen Genehmigung bedurften, und $\$ 8$, der den Behörden die Möglichkeit, Uniformverbote zu verhängen, offen ließ, hatten die Innenminister eine rechtliche Handhabe, um die Propaganda der NSDAP einzudämmen. ${ }^{157}$ Aus der Erfahrung heraus, dass die Verwendung von mobilen Gefährten Rechtsbrecher zu gewalttätigen Aktionen verleiten kann, weil sie sich dem Zugriff der Polizei rasch entziehen können, unterlagen NS-Propagandafahrten in Baden und Preußen der Anmeldepflicht. Die Genehmigung wurde mit Ausnahme von Wahlkampfzeiten häufig verweigert. ${ }^{158}$

Wie Wolfram Pyta in seiner Untersuchung „Gegen Hitler und für die Republik" ausführte, versuchten die sozialdemokratischen Innenminister die Suggestivkraft der NSDAP einzudämmen, indem sie den Einsatz der allerneuesten Propagandamittel wie Lautsprecherwagen, Kinowagen und Lichtreklame zumeist aus

153 Siehe die Ankündigung einer Kraftfahr-Relaisübung im September 1931, Schreiben der OSAF vom 2. 9. 1931, betr. Kraftfahr-Relais der Reichsleitung, BArch NS 24/110.

154 Vgl. Der Bayerische Staatsminister des Innern über die SA 1931, in: Bericht des bayerischen Staatsministers des Innern: „Die Nationalsozialistische Arbeiterpartei“, S. 25, BArch NS 26/317.

155 Vgl. ebenda, S. $19 \mathrm{ff}$.

156 Vgl. G. L. Wagener: Warum sollte ich verschweigen, S. 512, StadtA Hannover.

157 Vgl. Pyta: Gegen Hitler, S. 334.

158 Vgl. ebenda, S. 296, 345 f. Siehe beispielsweise den Ablehnungsbescheid der Polizeidirektion München vom 4.3. 1932 bezüglich des Antrages der NSDAP auf Erlaubnis zur Fahrt von Personenwagen in sämtlichen Teilen Münchens mit Transparenten zur Reichspräsidentenwahl. Die Ablehnung beruhte auf der Anordnung des Staatsministeriums des Innern vom 10.7.1931 und vom 29.9.1931, wonach alle politischen Versammlungen unter freiem Himmel, einschließlich der Aufzüge und Propagandafahrten, verboten werden können; StA München, Pol. Dir. München 6772. Gemäß Anordnung des Preußischen Innenministeriums untersagte die Regierung Arnsberg Aufzüge unter freiem Himmel zu politischen Zwecken. Gleichermaßen von den Verboten betroffen wie die NSDAP war die KPD, bisweilen auch das Reichsbanner und die Solidarität. Genehmigungen erfolgten 1932 zu Wahlzeiten und zu besonderen Gedenktagen; vgl. StA Münster, Regierung Arnsberg Nr. 14495. 
vorgeschobenen verkehrspolizeilichen Erwägungen verboten. 159 Die verhängten Maßnahmen gipfelten in der von Reichspräsident Heinrich Brüning erlassenen „Notverordnung zur Sicherung der Staatsautorität" vom 14. April 1932. Darin heißt es:

„Sämtliche militärähnlichen Organisationen der NSDAP (insbesondere die Sturmabteilungen, die Schutzstaffeln mit allen dazugehörigen Stäben und sonstigen Einrichtungen einschließlich der SA-Beobachter, SA-Reserven, Motorstürme, Marinestürme, Reiterstürme, des Fliegerkorps, Kraftfahrkorps, Sanitätskorps, der Führerschulen, der SA-Kasernen und der Zeugmeistereien) werden mit sofortiger Wirkung aufgelöst." 160

Als Folge des Verbots der SA und ihrer Unterabteilungen wurden Kraftwagen und -räder der Motorstürme und des NSKK, die für Zwecke der SA verwendet wurden, beschlagnahmt. ${ }^{161}$ Dass das NSKK offiziell unter die Hilfsverbände der SA eingereiht und aus diesem Grund verboten worden war, erfüllte die Mitglieder und Funktionsträger mit Genugtuung. Das Verbot beruhte nach Worten des Verlegers Theodor Oppermann auf der richtigen Erkenntnis des Gegners, dass „es sich hier nicht um einen beliebigen Kraftfahrerverband, sondern um eine politische Kampftruppe handelte" 162 . Ungeachtet des Statusgewinns des NSKK innerhalb der Bewegung bedeutete das Verbot der SA und ihrer Organisationen eine Behinderung der Propagandaaktivitäten. Die Maßnahmen zur Umgehung des Verbots, der Neuaufbau von Organisationen mit ähnlichen oder anders lautenden Namen stellten einen zusätzlichen Zeit-, Kosten- und Organisationsaufwand dar und verhinderten kurzzeitig ein öffentlichkeitswirksames Auftreten. Da nicht absehbar war, wie lange das Verbot andauern würde, riefen NSKK-nahe Kreise eine neue Vereinigung für nationalsozialistische Kraftfahrer ins Leben. Am 27. April 1932 erging der Aufruf zur Gründung des „Bundes Nationalsozialistischer Kraftfahrer" 163 . Angesprochen waren vor allem NSDAP-Mitglieder, die beruflich mit dem Kraftfahrwesen verbunden waren. Trotz der beruflich definierten Zielgruppe und der Konzentration auf wirtschaftspolitische Ziele lässt der Zeitpunkt und Personenkreis der Gründer darauf schließen, dass für das verbotene Kraftfahrkorps eine neue Dachorganisation geschaffen werden sollte. ${ }^{164}$ Nachdem das Verbot wieder aufgehoben worden war und das NSKK bereits Mitte Juni 1932 seine Arbeit fortsetzen konnte, wurde der „Bund Nationalsozialistischer Kraftfahrer“

159 Pyta: Gegen Hitler, S. 346.

160 Zit. nach Okrass: „Hamburg bleibt rot“, S. 267.

$161 \mathrm{Vgl}$. Anordnung des Regierungspräsidenten in Potsdam an alle Landräte und Oberbürgermeister vom 13. 4. 1932, BLHA Potsdam, Rep. 2A I Nr. 1111.

162 Oppermann: Unter den Sturmstandern, S. 60.

163 Vgl. Aufruf des Bundes Nationalsozialistischer Kraftfahrer e. V. vom 27. 4. 1932, BArch NS 24/242. Die Hamburger Marine-SA überdauerte das Verbot mit dem zeitweiligen Tarnnamen: Ruderklub „Blaue Jungs“; vgl. Krause: Hamburg wird braun, S. 152.

$164 \mathrm{Vgl}$. Aufruf des Bundes Nationalsozialistischer Kraftfahrer e. V. vom 27. 4. 1932, BArch NS 24/242. In dem Aufruf wurden nur zivile und unpolitische Ziele genannt: Die Beschaffung billiger Betriebsmittel, die Stellenvermittlung, der Nachweis von Garagen und Tankstellen, deren Betreiber Nationalsozialisten sind und die Gründung billiger Fahrschulen. 
aufgelöst. ${ }^{165}$ Auch die Motor-SA versuchte in der Verbotszeit ein Mindestmaß an Mobilität aufrechtzuerhalten. Der Dortmunder Motorsturm wurde beispielsweise unter dem Namen „Propagandaleitung Gruppe Dortmund“ weitergeführt. ${ }^{166}$

\section{Die Effektivität der nationalsozialistischen Motorisierungsbemühungen}

Der Zweck des NSKK bestand nach den Worten des stellvertretenden Korpsführers Adolf Hühnlein und gemäß den Satzungen in der Förderung des Aufstiegs der nationalsozialistischen Bewegung. So definierte Hühnlein das Korps im Juni 1932 in Abgrenzung zu den Clubs:

„Das Nationalsozialistische Kraftfahrkorps ist kein Automobilklub üblicher Art, der vornehmlich wirtschaftliche oder sportliche Ziele verfolgt. Es stellt dem deutschbewussten und opferbereiten Kraftfahrer die für unseres Volkes Zukunft entscheidend gewordene Hauptaufgabe: der Freiheitsbewegung zu dienen." ${ }^{167}$

Obwohl die Chronisten des Kraftfahrkorps die flächendeckende Einsatzbereitschaft des NSKK und der Motor-SA hervorhoben, waren 1932 Defizite erkennbar. Abstriche mussten durch die bereits genannten Organisations-, Uniformund Umzugsverbote, durch die Einbeziehung von Clubelementen und die Freiwilligkeit der Teilnahme an Übungen und Diensten hingenommen werden. Eine weitere Schwächung der politischen Einsatzfähigkeit ergab sich durch die Aufnahme fördernder Mitglieder ohne aktive Dienstleistung. Auch die Entwicklung der Motor-SA verlief trotz zentraler Befehlsgebung der OSAF in manchen Regionen recht schleppend. Erst im Wahljahr 1932 fanden in vielen Gauen die Vorbereitungen für den Aufbau der Motor-SA und des NSKK statt. Folglich waren die Motorstürme in einigen Regionen nur unwesentlich an den Propagandamaßnahmen der NSDAP beteiligt oder sie griffen frühestens im Laufe des Jahres 1932 in die Wahlkämpfe ein. Im Gau Westfalen-Süd, in Dortmund und in Schwerin waren erst im Herbst 1931 Anfänge des NSKK und der Motor-SA erkennbar. ${ }^{168}$ In Soest, Unna und im Sauerland formierten sich motorisierte Einheiten im Laufe des Jahres 1932. ${ }^{169}$ Auch die Entwicklung des Düsseldorfer NSKK und der Motor-SA kam bis zum Herbst 1931 nur langsam in Gang: Der Motorsturm bot nur 12 Motorräder, fünf Pkw und vier Lieferwagen auf. Der Regierungspräsident erklärte die mangelnde Beteiligung mit der Befürchtung der meisten Motorrad- und Autobesitzer, ihre Fahrzeuge könnten bei politischen Zusammenstößen beschädigt werden, wofür die Partei nicht aufkommen werde. ${ }^{170}$ Nur bei Großveranstaltungen sei es der Partei gelungen, die nötigen Kraftfahrzeuge aufzutreiben. ${ }^{171}$

\footnotetext{
165 Ab November 1932 wurden keine Mitgliedsbeiträge mehr erhoben; vgl. „Bund Nationalsozialistischer Kraftfahrer" vom 3. 11. 1932, BArch NS 24/110.

166 Vgl. Beck (Hrsg.): Kampf und Sieg, S. 144.

167 Völkischer Beobachter vom 26./27. 6. 1932: „Was will das Nationalsozialistische Kraftfahrkorps?".

168 Vgl. Beck (Hrsg.): Kampf und Sieg, S. 142, 144; Behrens: Mit Hitler zur Macht. S. 114.

169 Vgl. Beck (Hrsg.): Kampf und Sieg, S. 146.

170 Vgl. Franke: Der Aufstieg der NSDAP in Düsseldorf, S. 162.

171 Vgl. ebenda, S. 315, Anmerkung 661.
} 
Wo das NSKK und die Motorstürme jedoch in einer nennenswerten Stärke vertreten waren, lassen sich durchaus positive Effekte auf die Propaganda nachweisen: In vielen Orten Deutschlands und Österreichs ${ }^{172}$ warben die motorisierten Formationen vor Ort für die politischen Ziele der NSDAP und erreichten so eine Popularisierung ihrer Botschaft. Bei den Reichstagswahlen im September 1930 und den Märzwahlen 1933 ist ein Zusammenhang zwischen dem gewaltigen Propagandaaufwand der NSDAP und dem Wahlerfolg in München anzunehmen. ${ }^{173}$ Neben den Propagandafahrten übernahm das NSKK Sonderaufgaben. Glaubt man dem korpseigenen Mitteilungsblatt, so beförderte das NSKK 18000 SAMänner aus ganz Sachsen zum Chemnitzer Gauparteitag 1931.174 Wenn irgend möglich, verzichtete die SA ganz bewusst auf die Eisenbahn als Transportmittel, um die Unabhängigkeit von öffentlichen Verkehrsmitteln sicherzustellen und die An- und Abfahrt zu Werbezwecken nutzen zu können. Besonders im Rahmen der Wahlkampftournee Hitlers 1932 war das NSKK unersetzbar. Es übernahm z.B. die Beförderung der Pressevertreter beim Besuch Hitlers in Ostpreußen am 15. Juli $1932^{175}$ und die massenhafte Verteilung von Flugblättern vor dem Eintreffen Hitlers am Versammlungsort. ${ }^{176}$ Der Pressechef der NSDAP Otto Dietrich lobte das NSKK als „einzigartige Organisation“, die das „reibungslose verkehrstechnische Funktionieren “ der Terminplanung Hitlers gewährleistete. ${ }^{177}$

Der Ausbau der motorisierten Formationen wirkte sich spürbar auf die Veranstaltungsdichte in einigen Regionen aus. 1932 hatte sich die Zahl der Versammlungen in Oberfranken um ein Vielfaches erhöht. Die Gründe dafür lagen zum einen in der größeren Anzahl an Rednern, die ständig auf Bezirks- und Gauebene sowie in den Rednerschulen der Parteiorganisation und SA ausgebildet wurden, und zum anderen in der höheren Verfügbarkeit von Fahrzeugen, mit denen die Partei Veranstaltungen organisieren konnte. ${ }^{178}$ Allein in der westfälischen Kleinstadt Lippe fanden im Vorfeld der Kommunalwahl 1933 mit Hilfe des NSKK und der Motor-SA 800 Veranstaltungen der NSDAP statt. ${ }^{179}$

Auch wenn das NSKK und die Motor-SA für die Partei wichtige Propagandaund Transportaufgaben übernahmen, wäre es vermessen, die zunehmende Präsenz der motorisierten NSDAP-Verbände in der Stadt und auf dem Land als

172 Auch die Motorstaffel Wien war im Juli 1932 auf Propagandafahrt; vgl. Monatsbericht der Motorstaffel Wien für Juli 1932, OStA/AdR, 09, Kt. 19.

173 Vgl. Rösch: Die Münchner NSDAP, S. 544.

174 Vgl. Mitteilungsblatt für das Nationalsozialistische Kraftfahr-Korps und die Motorstürme der SA und SS vom 1. 8. 1931: „Das Kraftfahrkorps im Dienste des Chemnitzer Gauparteitags“, BArch NSD 42/3.

175 Vgl. Monatsblätter des NSKK vom Juli 1932.

176 Vgl. Paul: Aufstand der Bilder, S. 206. Die Verteilung von Flugblättern durch mobile SAEinheiten gehörte zum Standardprogramm bei Hitlers Wahlkämpfen 1932.

177 Vgl. Dietrich: Mit Hitler in die Macht, S. 67.

178 Vgl. Kühnel: Hans Schemm, S. 99. Zusätzlich war das NS-Kraftfahrkorps dem oberfränkischen Gauleiter Hans Schemm bei der Lösung eines logistischen Problems behilflich: Das Bayreuther NSKK stellte die von Schemm 1932 gegründete Tageszeitung in Oberfranken zu und lieferte sie bis nach Nürnberg und Würzburg; vgl. ebenda, S. 153.

179 Vgl. Blackbourn: „Die meisten von ihnen haben Räder“, S. 144. 
„pausenlosen Dynamismus“ 180 zu bezeichnen. Die zuvor genannten Hemmnisse und Beschränkungen verhinderten eine Allgegenwart der SA im öffentlichen Raum.

\section{Die Motorformationen wichtiger politischer Parteien und Webrverbände im Vergleich}

Um sich als Partei oder Wehrverband dauerhaft zu etablieren und in Konkurrenz $\mathrm{zu}$ anderen öffentlichen Verbänden treten zu können, war für alle Formationen ein Mindestmaß an organisatorischen Strukturen und logistischen Voraussetzungen unabdingbar. Der Einsatz von motorisierten Einheiten war aus drei rein pragmatischen Gründen für alle Gruppen gleichermaßen sinnvoll: Erstens, um Redner und Anhänger unabhängig von fremder Hilfe mit eigenen Fahrzeugen zu transportieren, zweitens, um die Nachrichtenübermittlung sicherzustellen und drittens, um den Radius der Propaganda und ihre Wirkung zu vergrößern.

\section{Kommunistische Motorradstaffeln}

Die KPD hatte die Werbemethoden auf ihre Zielgruppe, das städtische Proletariat, zugeschnitten. So lag der Schwerpunkt der Agitation in den Betrieben, den Nachbarschaften und in den Gewerkschaften. ${ }^{181}$ Vorwiegend in größeren Städten mobilisierte die KPD ihre Anhänger zu zahlreichen Demonstrationen. Um für ihre Belange zu werben und ihre politischen Positionen breiten Wählerschichten bekannt zu machen, waren auch die Kommunisten auf die Verbesserung ihrer Mobilität angewiesen. Als Reaktion auf den Erfolg der NSDAP im ersten Wahlgang zur Reichspräsidentenwahl am 13. März 1932, bei dem Hitler 30,1\% der Stimmen erringen konnte, forderte das Zentralkomittee von den Bezirken eine Verschärfung des Kampfes für den zweiten Wahlgang. Die "roten Sportler“ aller Sparten sollten durch Propagandafahrten zu Land und zu Wasser, durch Märsche und Sternläufe für die rote Einheitsfront und die Thälmann-Kandidatur werben. ${ }^{182}$ Selten wurde in den Anweisungen des Sekretariats an die Bezirke auf konkrete Propagandamethoden Bezug genommen. Eine Ausnahme stellte die Direktive vom 12. Oktober 1932 dar, in der für den Straßenkampf ausdrücklich gefordert wurde: „Die Möglichkeiten der Ausnutzung von Kino, Radio, Verkehrsmitteln und Verkehrsknotenpunkten müssen systematisch organisiert werden. "183 Die konkrete Umsetzung blieb jedoch den Bezirken überlassen. Vorwiegend zur Beförderung von Rednern und zur Nachrichtenübermittlung standen in den Reihen der Kommunisten Kraftfahrer bereit. Die KPD in Berlin verfügte im Oktober 1931 über 85 Motorräder und 33 Autos. ${ }^{184}$ Kommunistische Wehrverbände wie

180 Reichardt: Faschistische Kampfbünde, S. $117 \mathrm{f}$.

$181 \mathrm{Vgl}$. Neumann: Die Parteien der Weimarer Republik, S. $88 \mathrm{f}$.

$182 \mathrm{Vgl}$. Anweisungen des Sekretariats an die Bezirksleitungen vom 6. 4. 1932, in: Die Generallinie, Dok. 60, S. $473 \mathrm{ff}$.

$183 \mathrm{Vgl}$. Anweisungen des Sekretariats zur Wahlkampagne und Steigerung der Massenarbeit vom 12. 10. 1932, in: ebenda, Dok. 76, S. 587.

184 Vgl. Striefler: Kampf um die Macht, S. 286. 
der 1929 verbotene Rotfrontkämpferbund, der in der Illegalität weiterbestand, unterhielten neben Agitations-, Nachrichten-, Waffen- und Pioniergruppen auch Motorgruppen, die den Kurierdienst übernahmen und Material, Waffen und Personen transportierten. ${ }^{185}$

Das Polizeipräsidium Nürnberg-Fürth nahm in seinem politischen Lagebericht vom 28. Oktober 1932 den Aufbau von Motorstaffeln für Kurierdienste auf Seiten der Kommunisten alarmiert zur Kenntnis. ${ }^{186}$ Laut Mitteilung des Polizeipräsidiums Berlin vom 1. Oktober 1932 bekamen kommunistische Motorradfahrer bei der Tankstellen-Kette Derop (Deutsch-Russische-Oel-Produktions-Gesellschaft) aufgrund besonderer Ausweise Öl und Benzin mit 40\%igem Rabatt. Das Polizeipräsidium Nürnberg-Fürth wies darauf hin, dass Derop mit ihrem weit verzweigten Tankstellennetz bei der Durchführung eines kommunistischen Aufstandes nützlich sein könnte. ${ }^{187}$ Eine Denkschrift des Reichsministeriums des Innern über die „kommunistische Wühlarbeit im Winter 1932/33“ hielt fest, dass der KPD ein sorgfältig ausgebautes Netz von Kurieren zur Nachrichtenübermittlung zur Verfügung stehe, das in erster Linie von der „Roten Kavallerie“ getragen werde einem Zusammenschluss von Rad- und Motorradfahrern. ${ }^{188}$ Die Kommunisten beschränkten sich hauptsächlich auf die Bildung von Radfahr- und Motorradfahrerstaffeln. ${ }^{189}$ Die Staffeln waren lokal organisierte, lockere Vereinigungen, die keiner zentralen für Motorisierungsbelange zuständigen Instanz unterstanden. In manchen Orten existierten auch kommunistische Motorradvereine, die im Arbei-

$185 \mathrm{Vgl}$. ebenda, S. 226f. Bei illegalen Aktionen, beispielsweise bei den so genannten „Morden am Bülowplatz“ in Berlin im August 1931, bekamen die Berliner Gruppen auch Unterstützung durch eine Motorradfahrerstaffel aus Sachsen; vgl. ebenda, S. 257.

$186 \mathrm{Vgl}$. Sonderbericht der Polizeidirektion Nürnberg-Fürth vom 28. 10. 1932, S. 14 ff., StA Nürnberg, Pol. Dir. Nürnberg-Fürth Nr. 935.

$187 \mathrm{Vgl}$. ebenda, S. 17. Auch in der Kölner Organisation „Rot-Sport“ erhielten kommunistische Motorradfahrer bei Derop-Tankstellen Rückvergütungen, Kölnische Volkszeitung vom 23. 12. 1931: „Sowjetbenzin für Rot-Front“. Die Innenministerien der Länder hatten den Verdacht, dass Tankstellen der Derop-Stützpunkte der kommunistischen Partei seien, in denen Angestellte beschäftigt werden, die sich politisch und agitatorisch betätigen. Der Verdacht konnte im Frühjahr 1930 für Preußen nicht bestätigt werden; vgl. Nachricht des Preußischen Ministers des Innern an die Regierungspräsidenten vom 7.5. 1930, BLHA Potsdam, Rep. 2 Abt. I Pol. Nr. 1091. Nach den Ausführungen Strieflers stand die Derop völlig unter dem Einfluss des sowjetischen Geheimdienstes; vgl. Striefler: Kampf um die Macht, S. 217.

$188 \mathrm{Vgl}$. Denkschrift über die kommunistische Wühlarbeit im Winter 1932/33, Nachrichtensammelstelle des RIM vom 19. 4. 1933, BArch R 58/393.

189 In den Polizeiberichten über die KPD und ihre Organisationen wurden im Gegensatz zur NSDAP keine Motorformationen genannt, die als geschlossene Einheiten unter Beobachtung standen; vgl. Polizeipräsident Essen, Übersicht über die Kommunistische Partei und ihre Hilfs- und Nebenorganisationen vom 1. 9. 1932, StA Düsseldorf, Regierung Düsseldorf Nr. 17207. Die Bezirksleitung der KPD Ruhrgebiet forderte mit Schreiben vom 17. 10. 1932 alle Ortsgruppen und Stadtteile der Partei sowie Zellen auf, anlässlich der Reden des Genossen Thälmann am 25. Oktober in Dortmund und Essen, alle Kräfte zu aktivieren, um die Kundgebung zu einem „wuchtigen Bekenntnis für die Kommunistische Partei zu gestalten“. Die Vorbereitungsmaßnahmen sahen auch die Bildung von Radfahrkolonnen vor, die Propagandafahrten mit geschmückten Fahrrädern durchführen sollten; vgl. StA Düsseldorf, Regierung Düsseldorf Nr. 17184. 
ter-Kulturkartell organisiert waren. ${ }^{190} \mathrm{Da}$ die soziale Zusammensetzung der KPD-Mitglieder von Fabrikarbeitern und Arbeitslosen dominiert wurde, kam die Gründung einer eigenen Autofahrergruppe für die politische Agitation nicht in Betracht. Umso mehr, weil das Auto als Symbol der Bourgeoisie in kommunistischen Kreisen einen zweifelhaften Ruf genoss.

\section{Vielfalt statt Zentralismus: Motorformationen im Mitte-Links-Spektrum}

Die Wehrverbände der SPD waren hinsichtlich ihrer sozialen Zusammensetzung durchaus in der Lage, geschlossene Kraftfahrformationen zu bilden. Das Reichsbanner Schwarz-Rot-Gold, Bund deutscher Kriegsteilnehmer und Republikaner e. V., wurde 1924 als Gegengewicht zu den rechtsgerichteten Frontkämpferorganisationen gegründet. 1930 umfasste es rund 3,5 Millionen Mitglieder. Als einer der ersten Wehrverbände erkannte das Reichsbanner die Vorteile einer von Kraftfahrzeugen unterstützten Werbekampagne. Die Motorisierung erhöhte die Beweglichkeit, die Reichweite und die Öffentlichkeitswirksamkeit der Propaganda. Das Reichsbanner in Sachsen bediente sich 1925 aus Anlass der Reichspräsidentenwahl fahnengeschmückter Lastkraftwagen. ${ }^{191}$

Der Wehrverband unterhielt außerdem einen eigenen Nachrichtendienst mit paramilitärischem Charakter, der in geschlossenen Formationen auftrat und für die Bereitstellung von Kraftfahrzeugen sorgte. Im Zuge des Neuaufbaus des Nachrichten- und Verbindungswesens forderte die Reichsbannerleitung Franken 1929 von allen Ortsgruppen eine Auflistung der verfügbaren Kraftfahrzeuge von Mitgliedern und nahe stehenden Firmen. Im Notfall sollten sie die Autos in den Dienst des Reichsbanners stellen. ${ }^{192}$ Das Reichsbanner in München gründete im Frühjahr 1931 eine Kraftfahrformation mit 30 Mann, die bei Auseinandersetzungen mit dem politischen Gegner in Aktion trat. ${ }^{193}$ Des weiteren existierten zumindest vereinzelt Motorradstaffeln, die sich auch in den Wahlkämpfen 1932 engagierten. ${ }^{194}$ Das Fehlen einer zentralen Organisation aller motorisierten Einheiten im Reichsbanner dürfte jedoch die Logistik und den systematischen Aufbau eines Beförderungsdienstes erschwert haben.

Neben den Motorstaffeln innerhalb des Reichsbanners existierten weitere Organisationen des Flug- und Kraftfahrwesens, die der Sozialdemokratie nahe standen. Dies waren der „Deutsche Auto-Club“, der „Reichsverband Republikanischer Motorradfahrer e.V.“, der „Arbeiter-Rad- und Kraftfahrer-Bund Solidari-

190 Vgl. Mallmann: Kommunisten in der Weimarer Republik, S. 168.

191 Vgl. Schumann: Politische Gewalt in der Weimarer Republik 1918-1933, S. 246.

192 Vgl. Sonderbericht der Polizeidirektion Nürnberg-Fürth über die organisatorische Entwicklung des Reichsbanners, Nr. 162/II/29, S. 53, StA München, Pol. Dir. München 6890.

193 Vgl. Lagebericht der Polizeidirektion München vom 12. 3. 1931, StA Amberg, Regierung der Oberpfalz, KdI, Abgabe $1949 \mathrm{ff}$. Nr. 13907. Die Stammformation sollte Versammlungen vorbereiten und schützen. Als Leitfaden für die Ausbildung der Mitglieder in geschlossenen Formationen diente der "Technische Führer".

194 Vgl. Das Reichsbanner vom 16. 4. 1932: „Die Motorradstaffel unterwegs“. Die Motorstaffel Nordwest im Gau Berlin-Brandenburg fuhr mit 30 Motorrädern und 10 Wagen auf „Landagitation“. Es fanden kurze pro-Hindenburg-Ansprachen in den Dörfern statt. 
tät" und der Flugverband „Sturmvogel“. 195 Die Neugründungen in den Jahren 1928 und 1929 standen im Zusammenhang mit einer durchgreifenden Neuorganisation des Reichsbanners, dem es nach eigenem Urteil an Schlagkraft für größere Aktionen fehlte. Die Polizeidirektion Nürnberg-Fürth sah in der Gründung des Flugverbandes der Werktätigen „Sturmvogel“196, ebenso im Republikanischen Motorradfahrerverband und im Deutschen Autoclub, beispielhafte Versuche des Reichsbanners, Nebenorganisationen zu formieren, die zu einer Militarisierung des Reichsbanners führen könnten. ${ }^{197}$

Der Deutsche Auto-Club (DAC), der sich am 19. Januar 1928 in Berlin konstituiert hatte, verstand sich als „repräsentativer Automobil-Club der Deutschen Republik“. Die Gründung des DAC war eine direkte Reaktion auf die Weigerung der bestehenden Automobilclubs, insbesondere des ADAC, die neuen Reichsfarben in die Vereinsinsignien aufzunehmen. Hinter dieser vordergründigen Diskussion um die republikanischen Farben Schwarz-Rot-Gold contra alte Reichsflagge mit den Farben Schwarz-Weiß-Rot stand der Unwille der traditionellen Kraftfahrervereinigungen zur Begründung republikanischer Traditionen. ${ }^{198}$ Auch bei den preußischen Behörden erregte der ADAC-Clubwimpel mit den alten Reichsfarben Anstoß. ${ }^{199}$

195 Vgl. Organisationen von politischer Bedeutung. Zusammengestellt von der Polizeidirektion München nach dem Stande vom 1.3. 1930, S. $20 \mathrm{ff}$., StA Amberg, Regierung der Oberpfalz, KdI, Abgabe $1949 \mathrm{ff}$. Nr. 16375. Vgl. zu diesem Themenbereich auch die fünfbändige Untersuchung: Solidargemeinschaft und Milieu: Sozialistische Kultur- und Freizeitorganisationen in der Weimarer Republik. Sie liefert organisationsgeschichtlich profunde Einzelanalysen. Die hier genannten Organisationen wurden jedoch nicht einbezogen; vgl. den 1. Band: Walter: Sozialistische Akademiker- und Intellektuellenorganisationen in der Weimarer Republik.

196 Der „Sturmvogel“ wurde im April 1929 in Berlin gegründet. Vereinigungszweck war laut Satzung die Förderung der Luftfahrt unter der werktätigen Bevölkerung. Der Sturmvogel lehnte militärische Bestrebungen in der Luftfahrt $a b$ und verstand seine Existenz als Bekenntnis zur Weimarer Verfassung. Die Mitglieder beschäftigten sich vorwiegend mit Modell- und Segelflug und hatten die Möglichkeit, den Pilotenschein abzulegen. Politische Förderer kamen aus Gewerkschaftskreisen, der SPD und der DDP. Der Verband, gegliedert in Gaue und Ortsgruppen, umfasste 1930 rund 10000 und 193220000 Mitglieder und war der größte eigenständige Flugverein seiner Zeit in Deutschland. Am 12. 7. 1933 wurde er durch die Gestapo aufgelöst; vgl. Ferberg: Sturmvogel, S. 173-219.

197 Vgl. Sonderberichte der Polizeidirektion Nürnberg-Fürth vom 24.11. 1929, S. 53, StA Nürnberg, Pol. Dir. Nürnberg-Fürth Nr. 895, S. 49, 53.

198 Die Farben Schwarz-Rot-Gold waren die Farben der Revolution von 1848 und der Paulskirchenversammlung und standen symbolisch für eine nationale, freiheitliche, demokratische und auch großdeutsche Republik. Der Grund für die mangelnde Akzeptanz dieser Farben in der Weimarer Republik war nicht immer in der Verbundenheit zur monarchistischen Staatsform zu suchen, sondern ließ sich auch auf die nicht erfüllten nationalen Sehnsüchte und die Enttäuschung über die parlamentarische Staatsform zurückzuführen; vgl. Rohe: Das Reichsbanner Schwarz-Rot-Gold, S. 229, $241 \mathrm{ff}$.

199 Dem ADAC, Gau Pommern, wurde die Beihilfe für eine Fahrt anlässlich des Verfassungstages verweigert, weil bei der Bevölkerung der Eindruck entstehen könnte, es handle sich aufgrund des Clubwimpels um eine Demonstration gegen den Verfassungstag; vgl. das Schreiben des Oberpräsidenten der Provinz Pommern vom 31. 5. 1929 an den Preußischen Minister für Handel und Gewerbe und dessen Antwort an den Oberpräsidenten in Stettin vom 25. 6. 1929, R 58/326, Bl. $22 \mathrm{f}$. 
Die Träger des neuen Clubs sahen in ihrem Renegatentum ein Bekenntnis zum „wahren Deutschtum“: „Ein Deutscher Auto-Club sein heißt, sein Vaterland, also die Deutsche Republik und ihre Hoheitszeichen achten und ehren. " 200 Am Flaggenstreit ${ }^{201}$ und der anschließenden Abspaltung des DAC wird erkennbar, dass die Kluft zwischen den demonstrativen Befürwortern der Republik und den Verfechtern monarchistischer Traditionen auch das automobile Vereinswesen durchzog. Zugleich wird deutlich, dass auch der scheinbar unpolitische Freizeitsektor der bürgerlichen Mittel- und Oberschicht in der Weimarer Republik ein Forum und Spiegelbild gesellschaftlicher und politischer Legitimationsbestrebungen und Machtkämpfe war.

An der peniblen Mitgliederauswahl und an dem hohen Mitgliedsbeitrag von 30 RM kann man erkennen, dass der DAC keine mitgliederstarke Gegenorganisation unter Einbeziehung der Kleinbürger und der Arbeiter anstrebte. Im Unterschied zum „Sturmvogel - Flugverband der Werktätigen“, der dafür kämpfte, die „modernen Errungenschaften der Technik nicht länger den materiell bevorzugten Schichten allein zu überlassen“202, zählte die gesellschaftliche „Demokratisierung" des deutschen Kraftfahrwesens nicht zu den Zielen des DAC. Er setzte ein Zeichen republikanischer Gesinnungstreue, beharrte aber in seiner Zusammensetzung auf einem elitären Selbstverständnis. ${ }^{203}$

Von den anderen Automobilclubs unterschied sich der DAC in seiner Weigerung, gegen ausländische Kraftfahrzeuge zu polemisieren, deren Vorzüge sich seiner Ansicht nach nicht immer verkennen ließen. Außerdem lehnte der DAC den Rennsport als „luxuriöse Schaustellung" ab und trat für den "Gebrauchssport" ein. ${ }^{204}$ Als Präsident des DAC fungierte der Berliner Rechtsanwalt Dr. Arthur Brandt. Der Vorsitzende der Geschäftsstelle in Leipzig war der dort amtierende Polizeipräsident Heinrich Fleißner, den Vorsitz des DAC in Berlin hatte Rechts-

200 DAC. Der Deutsche Auto-Club wirbt um ihre Mitgliedschaft (Werbeschrift), 1929.

201 Die Flaggenfrage entwickelte sich in der Weimarer Republik zu einem Politikum. Das Reichsbanner strengte in vielen Bereichen des gesellschaftlichen Lebens einen „Flaggenstreit" an, den es zu einer Grundsatzentscheidung Republik versus Monarchie stilisierte. Der Historiker Karl Rohe wertete dies als „doktrinären Republikanismus“, ders.: Das Reichsbanner Schwarz-Rot-Gold, S. 244. Vgl. zum Thema Flaggenstreit auch Malvache: Die Lüdenscheider Arbeiterbewegung, S. 33. Kommunistische und sozialdemokratische Kreise reagierten zum Teil mit extremer Feindseligkeit auf die Schwarz-Weiß-Rot-Symbolik. Striefler berichtet, dass Kommunisten in Berlin 1931 einen Mann mit ADACMütze ermordeten, weil sich darauf die Farben der "Reaktion“ befunden haben; ders.: Kampf um die Macht, S. 343.

202 Zit. nach: Cordts: Junge Adler, S. 45.

${ }^{203}$ Sportverbände, die sich auch in ihrer Sportausübung zur republikanischen Staatsform bekannten, schlossen sich zum Deutschen Sportkartell zusammen. Mitglieder waren neben dem Deutschen Auto Club, der Deutsche Alpenverein, der Deutsche Republikanische Pfadfinderbund, der Deutsche Wassersportverband, der Deutsche Wintersportverband, der Freie Keglerbund Deutschland, Sturmvogel und der Arbeiter Turn- und Sportbund; vgl. Motorschau. Nationale Deutsche Motorfahrt Zeitung vom 15. 6. 1932: „Wissenswertes vom Gegner".

204 Vgl. DAC. Der Deutsche Auto-Club wirbt um ihre Mitgliedschaft (Werbeschrift), 1929. 
anwalt Dr. Adolf Hamburger inne. 205 Im Jahre 1931 wurde der Club in „Deutscher Reichs- Auto Club“ (DRAC) umbenannt und vom Magdeburger Oberpräsidenten Carl Falck (Deutsche Staatspartei) geleitet. In den Clubnachrichten warb der DRAC 1932 für die Wahl Hindenburgs und für die Republik. ${ }^{206}$ Die wichtigste Veranstaltung des DRAC war die alljährliche Verfassungsfeier, die er mit anderen republikanischen Vereinen beging. ${ }^{207}$

Personell eng mit dem DRAC verbunden war der 1929 in Leipzig gegründete „Reichsverband Republikanischer Motorradfahrer“, dem ebenfalls Polizeipräsident Fleißner in Leipzig und Rechtsanwalt Dr. Hamburger in Berlin vorstanden. Als Zweck der Vereinigung wird die „Zusammenfassung aller Motorradfahrer, die auf dem Boden der Weimarer Reichsverfassung stehen“, genannt. ${ }^{208}$ Man schuf nicht nur eine symbolische Verbindung mit dem Reichsbanner in Form einer Ehrenpräsidentschaft für den Bundesvorsitzenden des Reichsbanners Otto Hörsing, sondern forderte die Mitglieder aktiv auf, sich am Aufbau eines Nachrichten- und Alarmierungsdienstes zu beteiligen. ${ }^{209}$ Aufgrund der mangelnden Beteiligung löste sich der Verein am 15. Januar 1933 noch vor der NS-Machtübernahme selbst auf. 210

Ein hohes kraftfahrerisches Potenzial konnte sich auch in dem sehr populären Zweirad-Verband der Arbeitersportler, dem „Arbeiter-Rad- und KraftfahrerBund Solidarität", entfalten. Der 1896 mit Sitz in Offenbach ins Leben gerufene Verein entwickelte sich bis 1932 mit 350000 Mitgliedern zur größten Radsportorganisation der Welt. Aufgrund der Verbreitung des Motorrads in gehobenen Arbeiterkreisen ging man in den Reihen der "Solidarität“ ab Mitte der zwanziger Jahre gezielt dazu über, innerhalb der Ortsgruppen Motorradabteilungen aufzubauen. ${ }^{211}$ Unter den 314000 Mitgliedern der "Solidarität“ befanden sich 1930 nicht weniger als 29000 Motorradfahrer. Für die Motorradfahrer, von denen die meisten, sicherlich aufgrund des geringen Einkommens, Kleinkrafträder fuhren,

205 Vgl. Sonderberichte der Polizeidirektion Nürnberg-Fürth vom 24. 11. 1929, S. 51, StA Nürnberg, Pol. Dir. Nürnberg-Fürth Nr. 895.

206 Die Clubzeitschrift „Automobilia“ gab sich auch 1932 wenig parteipolitisch. Wie die anderen Clubzeitschriften legte sie den Schwerpunkt auf Technik, Reise und Mode. Die Beilage "Clubnachrichten des DRAC" hingegen forderte 1932 deutlich den Einsatz der Mitglieder für die Republik; vgl. Clubnachrichten des DRAC vom 10.4. 1932: „An die Mitglieder des Deutschen Reichs Auto-Clubs“. Auch der DRAC organisierte einen Fahrdienst zu den Wahllokalen.

207 Bei der Verfassungsfeier des republikanischen Sportkartells, zu der auch der DRAC gehörte, im Berliner Zoo 1931 waren der Reichstagpräsident Löbe, der Berliner Polizeipräsident Grzesinski und sein Vizepräsident Weiß sowie Kommandeur Heimannsberg anwesend; vgl. Automobilia vom 5. 9. 1931: „Verfassungsfeiern“ und „Deutsches Sportkartell“.

208 Vgl. Satzungen des Reichsverbandes Republikanischer Motorradfahrer, StA Leipzig, PPV 1724.

209 Vgl. Sonderberichte der Polizeidirektion Nürnberg-Fürth vom 24. 11. 1929, S. 52, StA Nürnberg, Pol. Dir. Nürnberg-Fürth Nr. 895.

$210 \mathrm{Vgl}$. Vereinsregisterauszug und Grundbuchauszug des Reichsverbandes Republikanischer Motorradfahrer, StA Leipzig, PPV 1724; Grundbuchauszug des Reichsverbandes Republikanischer Motorradfahrer, ebenda.

211 Vgl. Beduhn: Solidarität auf zwei Rädern, S. 131. 
war der Bund ein Ort der gemeinsamen Freizeitgestaltung. Er war kein Club, der den Mitgliedern wirtschaftliche und touristische Vorteile bot, aber auch keine politische Kampfgemeinschaft. ${ }^{212}$ Dennoch zählte der Rad- und Kraftfahrer-Bund "Solidarität" - eine Unterorganisation des „Arbeiter-Turn- und Sportbundes“ zu den SPD-nahen Kreisen, die zu den Unterstützern des Reichsbanners und der Eisernen Front gezählt werden können. Es ist belegt, dass Mitglieder der „Solidarität" bereits 1930 verschiedentlich zur Nachrichtenübermittlung herangezogen wurden. ${ }^{213}$

Eine größere Notwendigkeit, den Kraftwagen und das Motorrad in den Dienst der Politik zu stellen, ergab sich für die Arbeitersportler und Reichsbanner-Mitglieder erst mit dem Erfolg der Nationalsozialisten in den Septemberwahlen 1930 und dem Wahldebakel der SPD. Danach beschäftigten sich die Parteitheoretiker sehr ernsthaft mit den Gründen für den Aufstieg der NSDAP. Bei den Sozialdemokraten wurden Mängel in der Mobilisierbarkeit der Anhängerschaft deutlich. Alexander Schifrin arbeitete noch im selben Jahr mit großer analytischer Klarsicht die Besonderheiten in der politischen Taktik der Nationalsozialisten heraus:

„Die NSDAP ist die zentralisierteste unter allen deutschen Parteien. Sie verfügt über einen weitverzweigten Apparat, der unbeschwert durch ökonomische Interessenvertretung, sachliche Leistung und sozialen Dienst allein auf Agitation, Wählerfang und Massenbeeinflussung eingestellt ist. [...] Die NSDAP will die politische Technik reformieren. Sie versucht die schärfsten und effektivsten Einwirkungsmittel einzuführen. Das nationalsozialistische Plakat, die Zeitung und die Versammlungsrede haben ihre besonderen Züge, sie überraschen, verblüffen, hämmern ein. Diese Einwirkungsmittel werden mit einer in der politischen Geschichte Deutschlands unbekannten Intensität angewendet. [...] Nicht die physische Gewalt allein, sondern in erster Linie die Werbeleistung und die Intensität der politischen Technik haben dem deutschen Faschismus zu seinem Erfolg verholfen.214

Unter Hinweis auf die hinter der Sozialdemokratie stehende Masse forderte Schifrin ein größeres $\mathrm{Maß}$ an antifaschistischer Leidenschaft und politischem Sendungsbewusstsein bei den Mitgliedern ein. ${ }^{215}$ Er plädierte auch für die Verwendung agitatorischer und propagandistischer Mittel und warnte vor einem „Konservatismus in der Methodenwahl“".216 Das Abwehrbündnis zum Schutz der Republik, das sich am 16. Dezember 1931 unter dem Namen „Eiserne Front“ gegründet hatte, ${ }^{217}$ verwirklichte die Forderungen Schifrins nach einem neuen modernen Propagandastil, der die Gefühle der Menschen ansprechen sollte. Bei-

212 Obgleich das Fahrrad als das eigentliche Sportmittel zur „Verschönerung des Proletarierdaseins“ gepriesen wurde, waren Motorräder nicht als „unproletarisch“ verpönt. Die Mitglieder der 1300 Motorradabteilungen unternahmen Zuverlässigkeits- und Geschicklichkeitsfahrten und entrichteten einen jährlichen Mitgliedsbeitrag von acht RM; vgl. Arbeiter-Rad- und Kraftfahrer-Bund Solidarität: Festbuch, S. 14.

213 Vgl. Organisationen von politischer Bedeutung. Zusammengestellt von der Polizeidirektion München nach dem Stande vom 1.3. 1930, S. 37 f., StA Amberg, Regierung der Oberpfalz, KdI, Abgabe 1949 ff. Nr. 16375.

214 Schifrin: Parteiprobleme nach den Wahlen, S. 296.

215 Vgl. ebenda, S. $298 \mathrm{f}$.

216 Ebenda, S. $299 \mathrm{f}$.

217 Vgl. Brunner u.a.: Sozialdemokratische Partei und sozialdemokratisches Vereinswesen, S. $34 \mathrm{f}$. 
spielhaft dafür war die kurze prägnante, pathetische Versammlungsrede sowie die Einführung einer neuen Symbolsprache: das Kampfzeichen „Drei Pfeile“ und der Gruß mit der empor gestreckten Faust. ${ }^{218}$ Die Verwendung von Lautsprecherwagen und Tonfilmautos ermöglichte 1932 eine groß angelegte Verbreitung der sozialdemokratischen Wahlreden, und der Einsatz des Flugverbandes „Sturmvogel“ sorgte für einen flächendeckenden Abwurf von Flugblättern zur Preußenwahl im April 1932. ${ }^{219}$ In dem Zusammenschluss aus SPD, Reichsbanner, Freien Gewerkschaften und Arbeiter-Sportorganisationen erwuchs der SA ein kampfbereiter Gegner, dessen neuer Umgang mit den modernen Mitteln der Propaganda auch bei der NSKK-Korpsführung nicht unbeachtet blieb. Oppermann berichtete in den Monatsblättern vom April 1932, die Eiserne Front betreibe im ganzen Land eine „Riesenpropaganda“. So würden Motorkolonnen das Land systematisch mit Flugblättern belegen und mit Hilfe von Lautsprecherwagen die Reden von Hindenburg und Brüning übertragen. Oppermann appellierte an die Mitglieder der SA- und SS-Motorstürme: „Was die Motorkolonnen der Eisernen Front leisten können, das müssen und werden unsere Motorstürme und NSKK-Kolonnen erst recht vollbringen." 220

Der motorisierte Propagandaeinsatz der Nationalsozialisten und linksgerichteten Gruppen im Vergleich

Die Existenz und der Aufbau der bisher beschriebenen Motorformationen lassen folgende Schlussfolgerungen zu: Die Parteien und Verbände auf der linken Seite des politischen Spektrums unterhielten wie die NSDAP eigene motorisierte Einheiten und waren auf dem Gebiet des motorisierten Propagandaeinsatzes weder unfähig noch untätig. Das Reichsbanner setzte seine Motorradstaffeln und motorisierten Nebenorganisationen 1932 verstärkt für Zwecke der Landagitation ein. Eine Erklärung, warum die SPD und das Reichsbanner trotz aller Fortschritte in der Propaganda hinter den Nationalsozialisten zurückblieben, findet der Historiker Pyta, der die Auseinandersetzung der deutschen Sozialdemokratie mit der NSDAP in der Weimarer Republik untersucht hat, in der mangelhaften Organisationsstruktur und dem Fehlen eines eigenen Propagandaapparates auf Bezirksund Unterbezirksebene. ${ }^{221}$ Bis 1932 wirkten sich die unzulänglichen Verbindungsstrukturen negativ auf die Mobilität in den SPD-Gauen aus. Ein weiteres Problem, das im motorisierten Einsatz der Eisernen Front sichtbar wird, ist die Zersplitterung der Einsatzkräfte und ihrer Unterstützer. Im Gegensatz zur Motor-SA und zum NSKK konnte sich auf den Feldern der Nachrichtenübermittlung, der Propaganda und des Transports keine zentrale Organisation etablieren. Was in den Stabilitätsphasen einer Demokratie als Pluspunkt gewertet werden kann - die Pluralität der Gruppen und Ziele, ihre föderale und demokratische

218 Vgl. Ehls: Protest und Propaganda, S. 333.

219 Vgl. Pyta: Gegen Hitler, S. 418, 477. Bei den Reichstagswahlen im Juli 1932 warf er über Berlin 500000 Flugblätter ab; Ferberg: Sturmvogel, S. 189.

220 Monatsblätter des NSKK vom April 1932: „Rückblick und Ausblick“. Theodor Oppermann berichtet darin unter Bezugnahme auf das Berliner Tageblatt vom 31. 3. 1932.

221 Vgl. Pyta: Gegen Hitler, S. $516 \mathrm{f}$. 
Struktur -, erschwerte in den Krisenzeiten der Republik den Aufbau einer schlagkräftigen, zentral gesteuerten Organisation, der sich die unterschiedlichen Formationen unterzuordnen hatten. Politische Engstirnigkeit und das Beharren auf ideologischen Barrieren zwischen den Gewerkschaften, den Arbeitersportlern und dem Reichsbanner verhinderten eine Bündelung der Kräfte. Wie unversöhnlich sich die verschiedenen Kraftfahrorganisationen des gleichen politischen Flügels teilweise gegenüberstanden, zeigt folgende Episode: Die Motorradfahrerstaffel des Reichsbanners trat Anfang 1931 dem Deutschen Touring Club bei. Dieser Beitritt sorgte unter den Delegierten des Bezirkstages der Arbeiter-Rad-und Kraftfahrer für Entrüstung, da es sich beim Touring Club um einen deutschnationalen Club handelte. Die kommunistische „Neue Zeitung“ goss noch Öl ins Feuer, indem sie das Reichsbanner unter Faschismusverdacht stellte: „Die Motorradfahrerstaffel aber steht fahrtbereit bei den Deutschnationalen - um mit Vollgas die Fahrt ins ,Dritte Reich“ mitzumachen!“222

Die hierarchischen, reichseinheitlichen und zentralistischen Organisationsstrukturen des NSKK und der Motor-SA ließen eine derartige Fragmentierung innerhalb ihres Lagers nicht zu. Die zentrale Leitung hatte der von der OSAF beauftragte Inspekteur der SA- und SS-Motorstürme und stellvertretende Korpsführer des NSKK Adolf Hühnlein inne. Aufgrund der zentralen Befehlsgewalt und der einheitlichen Satzungen des NSKK und der Motor-SA waren die Organisationen eng miteinander verknüpft und an den Auftrag der SA gebunden. Seit 1930 setzten die Nationalsozialisten ganz bewusst auf den Einsatz motorisierter Kräfte im Demonstrationsgeschehen. Die Propagandaleitungen der Partei forderten aufgrund ihrer Erfahrungen zu dieser Zeit eine Erweiterung der Lastwagenpropaganda, da sie ein „nicht zu unterschätzendes Werbemittel“ sei. Die Sektionen könnten mit „Autos, die schlagkräftige Transparente und originelle Aufbauten aufweisen, große Erfolge erreichen". ${ }^{223}$ Die positive Resonanz ermutigte die Nationalsozialisten in ihrem Streben, Propaganda mit dem größtmöglichen technischen Aufwand zu gestalten. Sie betrieben den Aufbau und den Einsatz von Motorformationen sehr konsequent und erreichten einen hohen Organisationsgrad. Geregelte Dienste und Übungen förderten die Entwicklung einer eigenen Gruppenidentität unter den Mitgliedern der Motor-SA. Mit Motortreffen und gemeinsamen Fahrübungen auf Gausturmebene sollten Motorstürme und NSKKEinzelmitglieder ihre „Verwendungsfähigkeit“ erhöhen.224

Demgegenüber zeigten die Sozialdemokraten eine pragmatischere Herangehensweise im Umgang mit den modernen Transport- und Propagandamitteln. Bei Durchsicht der Zeitung „Das Reichsbanner“ des Jahrgangs 1932 fällt die spärliche Berichterstattung über die Motorradstaffeln auf. Im Gegensatz dazu wird in der Zeitschrift "Der SA-Mann“ von 1932 sehr häufig über die Entwicklung des

222 Neue Zeitung vom 26. 2. 1931: „Reichsbanner beim Touringclub gelandet“ (Presseausschnitt), StA München, Pol. Dir. München 6891.

223 Propaganda-Rundschreiben Nr. 16 vom 5. 8. 1930, StA München, Pol. Dir. München 6772. Die Parteigenossen sollten hierfür ihre Wagen zur Verfügung stellen.

$224 \mathrm{Vgl}$. Mitteilungsblatt für das Nationalsozialistische Kraftfahr-Korps und die Motorstürme der SA und SS vom 1.8. 1931: „Motortreffen“, BArch NDS 42/3. 
NSKK und der SA- und SS-Motorstürme berichtet. ${ }^{225}$ Das Bedürfnis nach Selbstdarstellung und werbewirksamer Ausstrahlung war bei den SA-Motorstürmern aufgrund ihrer Machtambitionen ungleich größer. Die Affinität der Nationalsozialisten zum motorisierten Propagandaeinsatz entwickelte sich auch deshalb so stark, weil der Motor das Erscheinungsbild der Partei als siegesgewisse, junge, kraftvolle Bewegung förderte und das Durchsetzungsideal der Nationalsozialisten - die Beherrschung des Staates durch die Eroberung der Straße - in idealer Weise verkörperte.

\section{Motorformationen im rechten politischen Spektrum}

Auf der rechten Seite des politischen Spektrums engagierten sich besonders die Wehrverbände „Stahlhelm" und „Wehrwolf“226 für den Aufbau und Einsatz motorisierter Einheiten. Die Entwicklung der Motorisierung innerhalb des Stahlhelms sollte für einen Vergleich mit den nationalsozialistischen Motorformationen näher betrachtet werden. Die Bundesleitung des Stahlhelms rief bereits im Oktober 1928, also fast zwei Jahre vor Gründung des „Nationalsozialistischen Automobilkorps“ und der Motor-SA, eine „Reichs-Kraftfahr-Staffel“ ins Leben. Der Stahlhelm, der zusammen mit dem Jungstahlhelm 1930 rund 400000 bis 500000 Mitglieder vereinigte, ${ }^{227}$ war der SA im Hinblick auf die Motorisierung nicht nur zeitlich voraus, sondern auch lange Zeit kräftemäßig überlegen. Im Jahre 1930 zählte die Staffel 4000 Fahrzeuge, davon $2800 \mathrm{Pkw}^{228}$ Das numerische Verhältnis von Personenwagen zu Motorrädern betrug also mehr als $2 \mathrm{zu} 1$ und ist Beleg für die gesicherte gesellschaftliche und wirtschaftliche Stellung der Angehörigen der Kraftfahrstaffel. ${ }^{229}$ Eine eigene motorisierte Formation passte in idealer Weise in das vom Stahlhelm kultivierte Vereinsleben mit regelmäßigen Paraden und Gedenkfeiern, wie z.B. dem Reichsgründungstag, den Geburtstagen von Hindenburg und Bismarck, dem Tag von Tannenberg und den jährlich stattfin-

225 In der Zeitung „Das Reichsbanner“ Jahrgang 1932 fällt nur einmal ein Hinweis auf eine Motorradstaffel ins Auge; vgl. Das Reichsbanner vom 16. 4. 1932: „Die Motorradstaffel unterwegs“. Der sozialdemokratische Deutsche (Reichs-) Autoclub (DRAC) wurde nicht erwähnt. Der SA-Mann, Jg. 1932, berichtet hingegen von zahlreichen Aktivitäten der Motorformationen, z.B.: Der SA-Mann vom 5.1. 1932: „Nationalsozialistische Kraftfahrer!“, vom 1.3. 1932: „Die braunen Fahrer, sie fliegen...“, vom 29.10. 1932: „Rund um Oberschlesien“, vom 12. 11. 1932: „Motorstaffel Wien“, vom 26. 11. 1932: "Wir fahren Propaganda“, vom 3. 12. 1932: „Berlins Motor-SA gedenkt der Toten“.

226 Der „Wehrwolf. Bund deutscher Männer und Frontkrieger“, spaltete sich 1923 vom Stahlhelm ab. In Gegnerschaft zur bürgerlich-parlamentarischen Republik erstrebte er eine militaristisch-autoritäre Diktatur. Der Wehrwolf hatte 1933 etwa 10000 Mitglieder; vgl. Finker u. a.: Wehrwolf. Er verfügte über eine eigene Kraftfahrstaffel, die dem „Ring der nationalen Motorfahrt" angeschlossen war; vgl. Autofreund vom Februar 1933.

227 Vgl. Berghahn: Der Stahlhelm, S. 286.

228 Vgl. Sonderbericht der Polizeidirektion Nürnberg-Fürth vom 9. 10. 1930, S. 21, StA Nürnberg, Pol. Dir. Nürnberg-Fürth Nr. 913.

229 Es wäre auch in diesem Fall verkürzend, von den Mitgliedern der Kraftfahrstaffel auf die Mitgliederstruktur des Gesamtstahlhelmes zu schließen. Der überwiegende Teil der Mitglieder bestand aus Angestellten und kleineren Beamten, der Anteil an Arbeitern dürfte bei 25-30\% gelegen haben; vgl. Klotzbücher: Der politische Weg des Stahlhelm, S. $42 \mathrm{ff}$. 
denden Frontsoldatentagen mit über 100000 uniformierten Beteiligten. ${ }^{230}$ Ende 1932 standen dem Stahlhelm 25000 Fahrzeuge zur Verfügung, deren Besitzer in 715 Motorstürmen organisiert waren. Diese Zahl entsprach zu dieser Zeit ungefähr der Stärke der Motor-SA. 231 Die Kraftfahrstaffel war nicht nur in der Lage, Angelegenheiten des Stahlhelms wie den Transport von Versammlungsteilnehmern zu übernehmen, sondern stellte sich auch für öffentliche Aufgaben im Rahmen der Katastrophenhilfe zur Verfügung. ${ }^{232}$ Durch die Gründung von Motorbootstaffeln und Segelflugtrupps dehnte sich der Stahlhelm auch auf andere Bereiche des Motor- und Flugwesens aus. 233

Um den nationalen Gedanken öffentlichkeitswirksam in das Kraftfahrwesen zu tragen, gründete die Reichskraftfahrstaffel des Stahlhelms 1929 den „Nationalen Deutschen Automobilklub“ (NDA). Der Führer der Reichskraftfahrstaffel Eduard Herzog von Sachsen-Coburg amtierte zugleich als Präsident des Clubs. Neben der Ämterbesetzung ist der Sitz der Geschäftsstelle des NDA bei der Bundesleitung des Stahlhelms ein klares Indiz für die enge Verbindung zwischen Wehrverband und Klub. ${ }^{234}$ Der Zweck des NDA war der Zusammenschluss „aller nationalen deutschen Kraftfahrer zu Lande, zu Wasser und in der Luft und solcher Persönlichkeiten, die ohne Fahrzeugbesitzer zu sein mit der Zielsetzung des NDA übereinstimmen“ und die „Überfremdung" des deutschen Motorwesens zu verhindern suchten. ${ }^{235}$ Die Ehrenmitgliedschaft des Prinzen Heinrich von Preußen und die Gründervereinigungen, darunter der Alldeutsche Verband, der Bund Oberland, die Deutsche Kraftfahrer-Offiziersvereinigung und der Deutsche Kolonialverein, verweisen auf die monarchistische, nationalistische und völkische Trägerschicht des NDA. Linksgerichtete Zeitungen, die den NDA mit Bezug auf die Fürstenenteignungen auch „Automobilklub arbeitsloser Fürsten“ nannten, warfen dem Club Heuchelei vor. Süffisant kommentieren sie das Hauptziel des Nationalen Deutschen Automobilclubs, nämlich das Einfuhrverbot ausländischer Erzeugnisse: „Das wird ja eine schöne Überschwemmung auf dem Automarkt geben, wenn die nationalen Herrschaften alle ihre ausländischen ,Tribut'wagen verkaufen!" 236 Der Vorwuf bezog sich auf die Vermutung, die Mitglieder des NDA würden privat ausländische Luxus-Wagen fahren, obwohl sie den Kauf derselben

230 Vgl. Fritzsche: Rehearsals for Fascism, S. 172, 176.

231 Vgl. Werner: SA und NSDAP, S. $551 \mathrm{f}$.

232 Vgl. Nord: Der Technische Dienst im Stahlhelm, S. 151.

233 Vgl. ebenda, S. 152. Es war geplant, die Segelflugtrupps zu einem „Stahlhelm-Fliegerkorps" zusammenzufassen.

$234 \mathrm{Vgl}$. Organisationen von politischer Bedeutung. Zusammengestellt von der Polizeidirektion München vom 1. 3. 1930, S. 102, StA Amberg, Regierung der Oberpfalz, KdI, Abgabe 1949 ff. Nr. 16375.

235 Bericht des Polizeipräsidiums Leipzig vom 13. 12. 1929, StA Leipzig, PPV Nr. 4255. Was unter einer "Nationalisierung des Motorwesens" verstanden werden sollte, zeigt das diffuse Zahlenspiel der "Verbrauchergemeinschaft Deutscher Kraftfahrzeuge“. Ein „deutsches“ Erzeugnis muss, so die Definition, aus einem deutschen Motor, aus $75 \%$ deutschem Material an Chassis und Karosserie und zu $75 \%$ aus deutscher Wertarbeit bestehen; Seherr-Thoss: Die Automobilindustrie, S. 226.

236 Presseausschnitt kommunistischer Herkunft von 1930 mit dem Titel „NDA“, in: StA Leipzig, PPV Nr. 4255 (NDA). 
öffentlich als illegitime „Tributzahlung“ an die Sieger des Ersten Weltkrieges brandmarkten. ${ }^{237}$

Im Unterschied zu den Kraftfahrstaffeln des Stahlhelms und zum NDA lehnten das NSKK und die Motor-SA es ab, ihre Fahrzeuge für Repräsentationszwecke zur Schau zu stellen oder sie für öffentliche Aufgaben bereitzuhalten. Insbesondere die Mitglieder der Motor-SA unterschieden sich in ihrem Selbstverständnis als kampflustige „Benzinhusaren“ von der behäbigen Kultiviertheit einer motorisierten Altherrenriege, wie sie die Kraftfahrstaffeln des Stahlhelms in ihrem Auftreten verkörperten. Der Motor war im nationalsozialistischen Kalkül auf seine Rolle als Kampf- und Propagandainstrument reduziert und wurde 1932 dauerhaft und gezielt zum Einsatz für politische Zwecke gebracht.

Trotz der Unterschiede gab es wesentliche Berührungspunkte zwischen dem Nationalen Deutschen Automobilclub und den nationalsozialistischen Kraftfahrern. Das NSAK gehörte dem NDA seit 1930 als Korporativclub an. ${ }^{238}$ Der Korpsführer begründete den Anschluss an einen Club mit dem gemeinsamen Ziel, die „Überfremdung des deutschen Marktes mit ausländischen Waren“ abzuwehren. Außerdem herrsche eine "seelische Verbundenheit" zwischen NSAK und NDA, die auf der gemeinsamen antijüdischen Einstellung beruhe. ${ }^{239}$ Gemeinsam war beiden Gruppierungen auch der undemokratische Aufbau. In den Satzungen des NDA war festgelegt: „Er [ $\operatorname{der} N D A]$ stellt den altgermanischen Führergedanken über das neudeutsche Beschlussrecht einer Masse oder Mehrheit."240

Jedes Mitglied des NSAK, ab 1931 NSKK, konnte die Einrichtungen des NDA mitbenutzen und von der Beschaffung verbilligter Grenzübertrittsscheine profitieren. ${ }^{241}$ Auf politischem Gebiet arbeiteten das NSKK und der NDA beim Volksentscheid am 9. August 1931 in Preußen zusammen. ${ }^{242}$ Dennoch blieb das Unbehagen des NSKK über die Mitgliedschaft in einem Club bestehen, weil sie in krassem Widerspruch zur Kampfhaltung des Korps gegen die „Vereinsmeierei“ der Automobilclubs stand. Gerechtfertigt erschien den NSKK-Verantwortlichen eine Kooperation vor allem aus wirtschaftlichen Motiven.243 Anfang 1932 löste

237 Vgl. die Satzung des NDA: „Der Kauf ausländischer Erzeugnisse erhöht freiwillig den Tribut“, BLHA Potsdam, Rep. 5E Nr. 901.

238 Weitere Korporativclubs des NDA waren die Reichskraftfahrstaffel des Stahlhelms, der Nationale Deutsche Damen Automobilclub und die Verbrauchergemeinschaft deutscher Kraftfahrzeuge - allesamt Ziehorganisationen des Herzogs von Sachsen-Coburg.

239 „Richtlinien für den weiteren Ausbau des NSAK“, abgedruckt in Oppermann: Unter den Sturmstandern, S. 26.

240 BLHA Potsdam, Rep. 5E Nr. 901.

241 Vgl. Satzungen des NSKK, $\$ 10$, Wirtschaftliche Vorteile, in: Oppermann: Unter den Sturmstandern, S. 32.

242 Vgl. Mitteilungsblatt für das Nationalsozialistische Kraftfahr-Korps und die Motorstürme der SA und SS vom 1. 8. 1931: „9. August! Sturm auf Preußen!“, BArch NSD 42/3. Nationalsozialistische Kraftfahrer sollten kranke Wähler mit dem Auto zur Abstimmung abholen und wahlberechtigte Personen von außerpreußischem Gebiet nach Preußen chauffieren. Als Würdigung des Einsatzes verlieh der Präsident des NDA das „Volksentscheid-Erinnerungszeichen“. Der vom Stahlhelm initiierte Volksentscheid über die Auflösung des preußischen Landtages erhielt mit 37,1\% nicht die erforderliche $50 \%$ Mehrheit.

243 Vgl. Völkischer Beobachter vom 13. 6. 1930: „Herein ins nationalsozialistische Automo- 
das NS-Kraftfahrkorps seine kooperative Mitgliedschaft im NDA auf. ${ }^{244}$ Das Korps und der Klub blieben sich aber in gemeinsamen Wahlkampfaktivitäten und im „Ring der nationalen Motorfahrt“" verbunden. Unter dem Kennwort „Tag der Nationalwirtschaft“ veranstaltete der „Ring der Nationalen Kraftfahrt- und Luftfahrtbewegung" und die "Verbraucher-Gemeinschaft Deutscher Kraftfahrzeuge“ Mitte November 1932 eine Tagung, die von zwei Leitgedanken getragen wurde: Die Förderung deutscher Erzeugnisse und die Förderung des „nationalen Gedankens ". ${ }^{245}$ Obgleich der stellvertretende Korpsführer des NSKK versprach, an diesen Bestrebungen mitzuarbeiten, machte Hühnlein, ähnlich wie Hitler auf dem Treffen der Harzburger Front am 11. Oktober 1931, sehr deutlich, dass die nationalsozialistischen Kraftfahrer sich nicht als Gleiche unter Gleichen in die nationale Front der Kraftfahrer einreihen werden. Ihr Hauptziel, so Hühnlein, bestehe in der „Beseitigung des Systems“.246 Hühnleins Fundamentalopposition erteilte somit den Reformvorstellungen und dem nationalen Lobbyismus des NDA im Bereich der Kraftverkehrswirtschaft eine klare Absage. Die kompromisslose Strategie wirkte sich für das NSKK offenbar nicht nachteilig aus, denn der wichtigste Vertreter der nationalen Kraftfahrt, der Gründer und Organisator des NDA und des „Ringes der nationalen Kraftfahrt“ Carl Eduard Herzog von Sachsen-Coburg befürwortete bereits Ende 1931 ein Zusammengehen von Stahlhelm und NSDAP und erwarb 1932 die Mitgliedschaft des NSKK. ${ }^{247}$

Die Kraftfahrstaffeln der rechten Verbände waren aus Sicht des NSKK eine unliebsame Konkurrenz, nicht aber politische Gegner wie das Reichsbanner und die Kommunisten, die es vor 1933 zu bekämpfen und nach der Machtübernahme auszuschalten galt. So war der Weg zur Aufnahme der Stahlhelm- und WehrwolfKraftfahrstaffeln in das NSKK und die Motor-SA zu Beginn des „Dritten Rei-

bil-Korps“. Der Beitritt zum NDA wurde zwar als „unsympathisch“ bezeichnet, doch mit den wirtschaftlichen Interessen der Korpsmitglieder begründet.

$244 \mathrm{Vgl}$. Schreiben von Kraus an den Motorsturmführer Fetzer vom 2. 2. 1932, BArch NS 24/ 110. Kraus verwandte hier wahrscheinlich versehentlich die Abkürzung „NAC“ statt „NDA“.

245 Monatsblätter des NSKK vom Dezember 1931: „Reichsführertagung der Nationalen Motorfahrt".

246 Ebenda.

247 Carl Eduard Herzog von Sachsen-Coburg (1884-1954), geb. in Clairmont-Esher (Surrey), bis 1900 Eton College, Hauptkadettenanstalt Lichterfelde, im Ersten Weltkrieg zuletzt Infanteriegeneral, 1905 Übernahme der Regierung in Sachsen-Coburg und Gotha, 1918 Abdankung, 1919 Bayerische Einwohnerwehr, 1920 Brigade Wiking, 1926-1933 Stahlhelm-Führer, seit 1932 Mitglied beim NSKK, 1932 Verweis von der Bundesleitung des Stahlhelms wegen seines Eintretens für Hitler, ab März 1933 vorübergehend Reichsbeauftragter für das Kraftfahrwesen, 1.5. 1933 Beitritt zur NSDAP, August 1933 SAGruppenführer im Stabe der Obersten-SA-Führung, ab Dezember 1933 Präsident des Deutschen Roten Kreuzes, 1950 in der Berufung des Entnazifizierungsverfahrens als minderbelastet eingestuft; vgl. Hambrecht: Der Aufstieg der NSDAP in Mittel- und Oberfranken, S. 558, Anmerkung 375; Oltmann: „Seine Königliche Hoheit der Obergruppenführer". 
ches" genauso vorgezeichnet wie die Zerschlagung sämtlicher Motorformationen mit linksgerichtetem Hintergrund. 248

248 Vgl. zu den unterschiedlichen "Gleichschaltungsprozessen“ der genannten Gruppierungen nach der NS-Machtübernahme S. 191 f. und S. 403 f. dieser Arbeit. 